\title{
Cross-Inhibition of NMBR and GRPR Signaling Maintains Normal Histaminergic Itch Transmission
}

\author{
Zhong-Qiu Zhao, ${ }^{1,2 *}$ Li Wan, ${ }^{1,2,7 *}$ Xian-Yu Liu, ${ }^{1,2 \star}$ Fu-Quan Huo, ${ }^{1,2 *}$ (1) Hui Li, ${ }^{1,2,8 *}$ @Devin M. Barry, ${ }^{1,2}$ Stephanie Krieger, ${ }^{5}$ \\ Seungil Kim, ${ }^{1,2}$ Zhong-Chun Liu, ${ }^{1,2}$ Jinbin $\mathrm{Xu},{ }^{6}$ Buck E. Rogers, ${ }^{5}$ Yun-Qing Li, ${ }^{8}$ and Zhou-Feng Chen ${ }^{1,2,3,4}$ \\ ${ }^{1}$ Center for the Study of Itch, and Departments of ${ }^{2}$ Anesthesiology, ${ }^{3}$ Psychiatry, ${ }^{4}$ Developmental Biology, ${ }^{5}$ Radiation Oncology, and ${ }^{6}$ Radiology, Washington \\ University School of Medicine, St. Louis, Missouri 63110, ${ }^{7}$ Department of Anesthesiology, The Second Affiliated Hospital, Guangzhou Medical University, \\ Guangzhou, Guangdong 510260, People's Republic of China, and ${ }^{8}$ Department of Anatomy, Histology and Embryology, and K. K. Leung Brain Research \\ Centre, The Fourth Military Medical University, Xi'an, Shaanxi 710032, People’s Republic of China
}

We previously showed that gastrin-releasing peptide receptor (GRPR) in the spinal cord is important for mediating nonhistaminergic itch. Neuromedin B receptor (NMBR), the second member of the mammalian bombesin receptor family, is expressed in a largely nonoverlapping pattern with GRPR in the superficial spinal cord, and its role in itch transmission remains unclear. Here, we report that $\mathrm{Nmbr}$ knock-out (KO) mice exhibited normal scratching behavior in response to intradermal injection of pruritogens. However, mice lacking both $\mathrm{Nmbr}$ and $\mathrm{Grpr}$ (DKO mice) showed significant deficits in histaminergic itch. In contrast, the chloroquine (CQ)-evoked scratching behavior of DKO mice is not further reduced compared with Grpr KO mice. These results suggest that NMBR and GRPR could compensate for the loss of each other to maintain normal histamine-evoked itch, whereas GRPR is exclusively required for CQ-evoked scratching behavior. Interestingly, GRPR activity is enhanced in Nmbr KO mice despite the lack of upregulation of Grpr expression; so is NMBR in Grpr KO mice. We found that NMB acts exclusively through NMBR for itch transmission, whereas GRP can signal through both receptors, albeit to NMBR to a much lesser extent. Although NMBR and $\mathrm{NMBR}^{+}$neurons are dispensable for histaminergic itch, GRPR ${ }^{+}$ neurons are likely to act downstream of $\mathrm{NMBR}^{+}$neurons to integrate NMB-NMBR-encoded histaminergic itch information in normal physiological conditions. Together, we define the respective function of NMBR and GRPR in itch transmission, and reveal an unexpected relationship not only between the two receptors but also between the two populations of interneurons in itch signaling.

Key words: cross-inhibition; GRP; GRPR; itch; NMB; NMBR

\section{Introduction}

Dorsal horn neurons of the spinal cord integrate and transduce pain, itch, and temperature signals from the primary afferents to the somatosensory cortex (Todd, 2010; Braz et al., 2014). Primary afferents detect, process, and relay itch information from the skin

Received April 28, 2014; revised Aug. 4, 2014; accepted Aug. 5, 2014.

Author contributions: Z.-Q.Z., X.-Y.L., J.X., B.E.R., and Z.-F.C. designed research; Z.-Q.Z., L.W., X.-Y.L., F.-Q.H., H.L., D.M.B., S. Krieger, S. Kim, Z.-C.L., and J.X. performed research; J.X. and Y.-Q.L. contributed unpublished reagents/analytic tools; Z.-Q.Z., J.X., B.E.R., and Z.-F.C. analyzed data; X.-Y.L. and Z.-F.C. wrote the paper.

This research was supported by the National Natural Science Foundation of China (Grants 81371239 and 31371211) and R01 Grant AR056318-01A1 from the National Institute of Arthritis and Musculoskeletal and Skin Diseases of the National Institutes of Health (to Z.-F.C.). We thank Ohki-Hamazaki for $\mathrm{Nmbr}^{+/-}$and Brs3 ${ }^{+/-}$mice; and J. Yin, L.R. Han, Q. Li, and P. Mo for behavioral tests and technical support. We also thank Y. Sun for initial help with the neuromedin $B$ receptor project, and members of the Chen laboratory for their comments.

*Z.-Q.Z., L.W., X.-Y.L., F.-Q.H., and H.L. contributed equally to this work.

The authors declare no competing financial interests.

Correspondence should be addressed to Dr. Zhou-Feng Chen, Center for the Study of Itch, Departments of Anesthesiology, Psychiatry and Developmental Biology, Washington University School of Medicine, St. Louis, M0 63110. E-mail: chenz@wustl.edu.

S. Kim's present address: Department of Cell and Tissue Biology, Craniofacial and Mesenchymal Biology, University of California, San Francisco, CA 94143.

Z.-C. Liu's present address: Department of Psychiatry, Renmin Hospital, Wuhan University, Wuhan 430060, People's Republic of China.

F.Q. Huo's present address: Department of Physiology and Pathophysiology, Xi'an Jiaotong University School of Medicine, Xi'an, Shaanxi 710061, People's Republic of China.

DOI:10.1523/JNEUROSCI.1709-14.2014

Copyright $\odot 2014$ the authors $\quad 0270-6474 / 14 / 3412402-13 \$ 15.00 / 0$ through a wide array of molecular sensors such as G-proteincoupled receptors and transient receptor potential (TRP) channels in dorsal root ganglion (DRG) neurons (Han and Simon, 2011; Jeffry et al., 2011; Bautista et al., 2014). DRG neurons release glutamate and neuropeptides to activate postsynaptic receptors in the spinal cord to relay itch information (Jeffry et al., 2011; Akiyama and Carstens, 2013). Itch sensation can be classified as histamine dependent and histamine independent. Gastrin-releasing peptide (GRP) in DRG neurons activates its receptor (GRPR) in the spinal cord to relay nonhistaminergic itch, whereas its role in histaminergic itch is dispensable or relatively minor (Sun and Chen, 2007; Koga et al., 2011; Akiyama et al., 2014). Spinal laminae I and II neurons expressing GRPR are essential for relaying acute histaminergic and nonhistaminergic itch as well as long-lasting itch transmission (Sun et al., 2009; Zhao et al., 2013). These studies, however, beg the question as to which neuropeptide is involved in mediating histaminergic itch from the primary afferents to $\mathrm{GRPR}^{+}$neurons in the spinal cord. B-type natriuretic peptide (BNP) and its receptor natriuretic peptide receptor-A (NPRA) have been proposed to act upstream of GRP-GRPR signaling (Mishra and Hoon, 2013). However, other studies found that the BNP-NPRA pathway is important for nociceptive processing and is independent of the GRP-GRPR pathway (Zhang et al., 2010; Vilotti et al., 2013; Liu et al., 2014). 
GRPR (or BB2) is a member of the mammalian bombesin $(\mathrm{Bn})$ receptor family, which comprises the following two other receptor subtypes: neuromedin B receptor [NMBR (or BB1)] and bombesin receptor subtype 3 (BRS-3). The latter is a distantly related member with little binding affinity to NMB or GRP (Battey and Wada, 1991; Kroog et al., 1995; Gonzalez et al., 2008; Jensen et al., 2008). GRP is expressed in $\sim 8 \%$ of DRG neurons and $12 \%$ of trigeminal ganglion neurons that coexpress TRPV 1 in rodents and is upregulated in chronic itch conditions (Sun and Chen, 2007; Zhao et al., 2013; Liu et al., 2014; Takanami et al., 2014). Similar to GRP, intrathecal injection of NMB could also induce scratching behavior (O'Donohue et al., 1984; Bishop et al., 1986; Moody and Merali, 2004; Su and Ko, 2011). A major obstacle in investigating the molecular coding of somatosensory transduction using genetic knock-out (KO) mice and/or pharmacological approaches is the multiplicity of a receptor family, which was hypothesized to arise from duplication and divergence of a common ancestor genome (Holland et al., 1994; Miklos and Rubin, 1996). Pharmacological approaches using GRPR or NMBR antagonists may suffer from inherent problems that could result in misinterpretation of the data because these antagonists could function as agonist, partial agonist, or nonspecific antagonists, or the GRPR antagonist may function as an agonist for NMBR or vice versa (Jensen et al., 2008). On the other hand, the relatively minor phenotype of $\mathrm{Nmbr}^{-1-}$ mice has been attributed to genetic/developmental compensation, even in the absence of upregulation of other bombesin-related receptors (Ohki-Hamazaki et al., 1999; Ohki-Hamazaki, 2000).

In this study, we define the respective roles of NMB-NMBR and GRP-GRPR signaling in itch transmission using a combination of pharmacological and genetic approaches in mice. Moreover, we delineate the relationship between the two receptors as well as $\mathrm{NMBR}^{+}$ and $\mathrm{GRPR}^{+}$neuronal functions in the spinal cord.

\section{Materials and Methods}

Mice. Male mice between 7 and 12 weeks of age were used for experiments. C57BL/6J mice were purchased from The Jackson Laboratory (http://jaxmice.jax.org/strain/013636.html). $\mathrm{Nmbr}^{-/-}$mice (OhkiHamazaki et al., 1999), Grpr KO mice (Hampton et al., 1998), NMBeGFP mice (MMRRC), NMBR-eGFP mice (MMRRC), and their wild-type (WT) littermates were used. Grpr/Nmbr double-knock-out mice were generated by crossing $\mathrm{Nmbr}^{-1-}$ mice with $\mathrm{Grpr} \mathrm{KO}$ mice. We validated NMBR-eGFP mice using single-cell reverse transcription-PCR (RT-PCR). All eGFP ${ }^{+}$neurons picked from spinal sections showed expression of Nmbr mRNA, but not Grpr mRNA ( $n=9$; data not shown). All mice were housed under a $12 \mathrm{~h}$ light/dark cycle with food and water provided ad libitum. All experiments were performed in accordance with the guidelines of the National Institutes of Health and the International Association for the Study of Pain, and were approved by the Animal Studies Committee at Washington University School of Medicine.

Drugs and reagents. Histamine, compound 48/80, 5-HT, chloroquine (CQ), bovine adrenal medulla $8-22$ peptide (BAM8-22), and capsaicin were purchased from Sigma-Aldrich. $\mathrm{GRP}_{18-27}, \mathrm{NMB}$, and bombesin were purchased from Bachem. Bombesin-saporin (Bn-sap) and blank-saporin were made by Advanced Targeting Systems. Resiniferatoxin (RTX) was from Fisher Scientific. Capsaicin was first dissolved in ethanol followed by further dilution in sterile saline solution. The final concentration for ethanol was $2 \%$. Other drugs were dissolved in sterile saline solution.

Behavioral tests. Behavioral tests were videotaped (HDR-CX190 camera, Sony). The videos were played back on a computer, and the quantification of mice behavior was performed by persons who were blinded to the treatments and genotypes.

Scratching behavior. Itch behaviors were performed as previously described (Sun and Chen, 2007; Sun et al., 2009). Briefly, before experiments, mice were given $30 \mathrm{~min}$ to acclimate to the plastic arenas $(10 \times$
$10.5 \times 15 \mathrm{~cm})$. Mice were then briefly removed from the chamber for drug injections.

Ablation of TRPV1 $1^{+}$fibers. C57BL/6J mice were treated with RTX (25 ng in $5 \mu$ l solution, i.t.) for $7 \mathrm{~d}$ as previously described, with modification in the dose of RTX (Jeffry et al., 2009).

Acute nociceptive behavior. Capsaicin was intraplantarly injected into the right hindpaw. The duration of licking and flinching of the injected paw was recorded for 5 min.

Immunohistochemistry and in situ hybridization. Immunohistochemistry (IHC) staining was performed as described previously (Chen et al., 2001; Zhao et al., 2006). Briefly, mice were anesthetized with an overdose of a ketamine/xylazine cocktail and fixed by intracardiac perfusion of cold 0.01 м PBS, pH 7.4, and 4\% paraformaldehyde. Tissues were immediately removed, postfixed in the same fixative overnight at $4^{\circ} \mathrm{C}$, and cryoprotected in 30\% sucrose solution. Tissues were frozen and sectioned at $20 \mu \mathrm{m}$ thickness on a cryostat. Free-floating sections were blocked in a solution containing $2 \%$ donkey serum and $0.3 \%$ Triton $\mathrm{X}-100$ in PBS for $1 \mathrm{~h}$ at room temperature. The sections were incubated with primary antibodies or fluorescein isothiocyanate (FITC)-conjugated Isolectin B4 Griffonia simplicifolia (IB4) overnight at $4^{\circ} \mathrm{C}$ followed by secondary antibodies. The secondary antibodies were purchased from Jackson ImmunoResearch Laboratories including Cy3- or FITCconjugated donkey anti-rabbit or anti-mouse IgG (Cy3, $0.5 \mu \mathrm{g} / \mathrm{ml}$; FITC, $1.25 \mu \mathrm{g} / \mathrm{ml}$ ), biotin-SP (long-spacer)-conjugated donkey anti-chicken or anti-rabbit IgG $(1 \mu \mathrm{g} / \mathrm{ml})$ and Alex Fluor 488 -avidin $(0.33 \mu \mathrm{g} / \mathrm{ml})$. In situ hybridization (ISH) was performed using digoxigenin-labeled cRNA probe as previously described (Chen et al., 2001). For antibody staining after ISH of Nmb, vesicular glutamate transporter 2 ( Vglut2), and glutamic acid decarboxylase 67 (Gad67), the sections were incubated with rabbit anti-GFP antibody followed by biotin-SP-conjugated donkey antirabbit IgG, and the color was developed using 3,3'-DAB. Images were taken using a Nikon Eclipse Ti-U microscope or a confocal microscope. The staining was quantified by a person blinded to the treatments and genotypes using ImageJ (version 1.34e, NIH Image), as previously described (Zhao et al., 2013). We counted only individual cells with clear nuclei that were above background staining. At least three mice per group and 10 sections across each tissue were included for statistical comparison.

Antibodies specificity. The following primary antibodies were used at the specified concentrations. The chicken polyclonal GFP antiserum (20 $\mu \mathrm{g} / \mathrm{ml}$; GFP-1020, Aves Labs) was analyzed by Western blot analysis and immunohistochemistry using transgenic mice expressing the GFP gene product (from the manufacturer's datasheet). GFP immunostaining was not detected in the gut of wild-type mice (Zylka et al., 2005; Erickson et al., 2012).

The rabbit polyclonal GFP antiserum (1:500; A-6455, Life Technologies) was analyzed by Western blot analysis demonstrating a single band at $\approx 30 \mathrm{kDa}$. No immunofluorescence was detected on brain sections lacking GFP transgene (Wang and Hazelrigg, 1994; Tseng et al., 2010).

The calcitonin gene-related peptide $(\mathrm{CGRP} \alpha)$ antiserum (rabbit, 1:3000; AB1971, Millipore Bioscience Research Reagents) was developed against the whole-rat CGRP $\alpha$ conjugated to BSA. Preadsorption with the full CGRP peptide $(10 \mu \mathrm{M})$ completely blocked staining in control DRG sections (Grill et al., 1997; Woodbury et al., 2008).

The GRPR mouse monoclonal antibody $(0.4 \mu \mathrm{g} / \mathrm{ml})$ was custom made via Abmart. The GRPR rabbit polyclonal antibody $(0.33 \mu \mathrm{g} / \mathrm{ml}$; LS-A831, $\mathrm{MBL}$ ) was raised against a synthetic 17 aa peptide from the third cytoplasmic domain of human GRPR. HEK 293 cells expressing GRPR, but not NMBR, were specifically labeled by GRPR antibodies. No immunofluorescence was detected on spinal sections from mice treated with bombesin-saporin. Preadsorption with antigen completely blocked staining in control spinal sections (data not shown).

The $\gamma$ isoform of protein kinase C (PKC $\gamma$ ) rabbit polyclonal antibody $(0.4 \mu \mathrm{g} / \mathrm{ml}$; sc-211, Santa Cruz Biotechnology) produced two closely spaced bands in Western blots prepared from rat cerebellum and neocortex, with an approximate molecular weight of $80 \mathrm{kDa}$ (Cardell et al., 1998). Labeling in the Western blots was eliminated by preadsorption with the immunizing peptide (Osada et al., 1992; Marvizón et al., 2009). 


\section{A $N m b / G F P$}

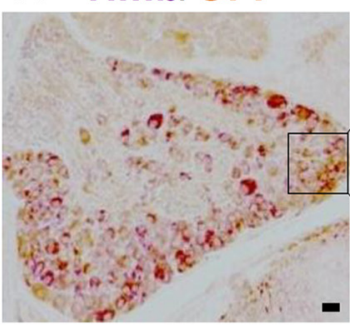

C 2 weeks

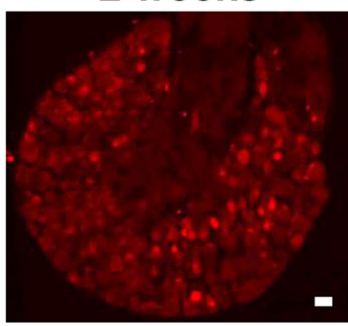

Marker
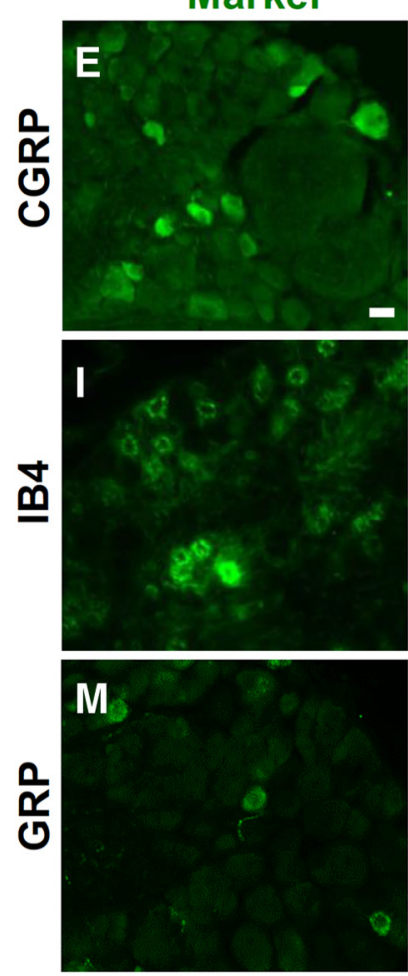
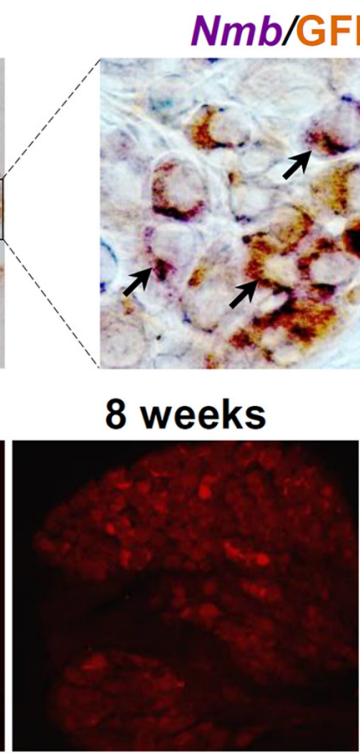

NMB
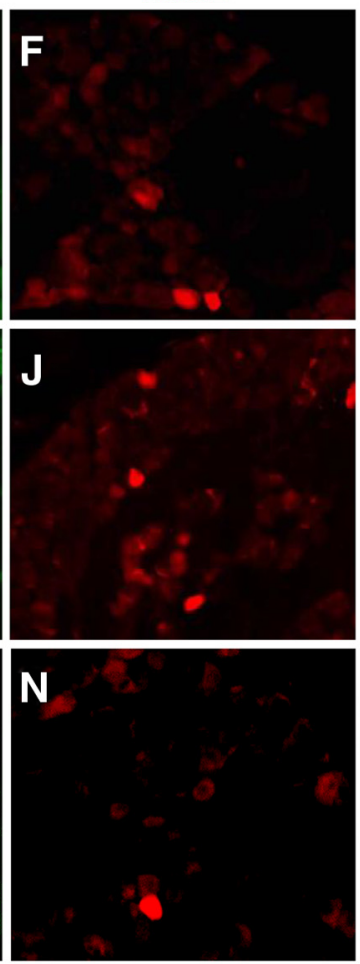

$\mathrm{Nmb/GFP}$

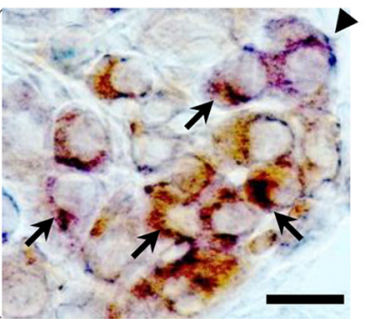

B
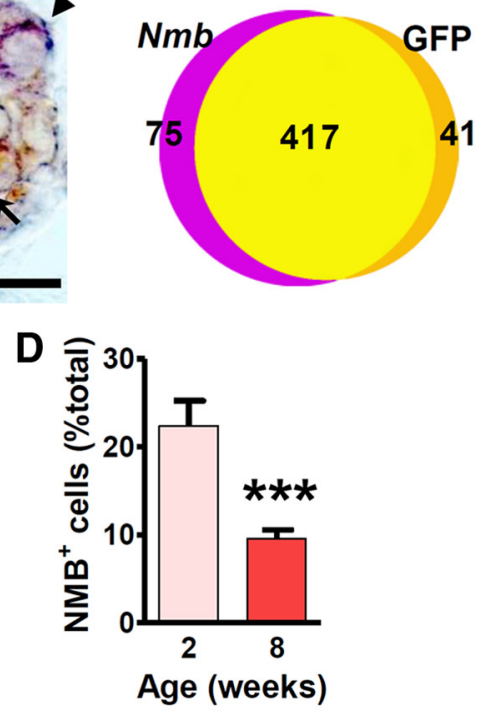

\section{Marker/NMB}

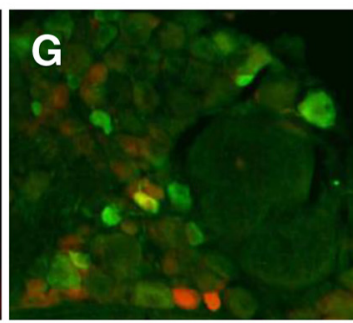

H
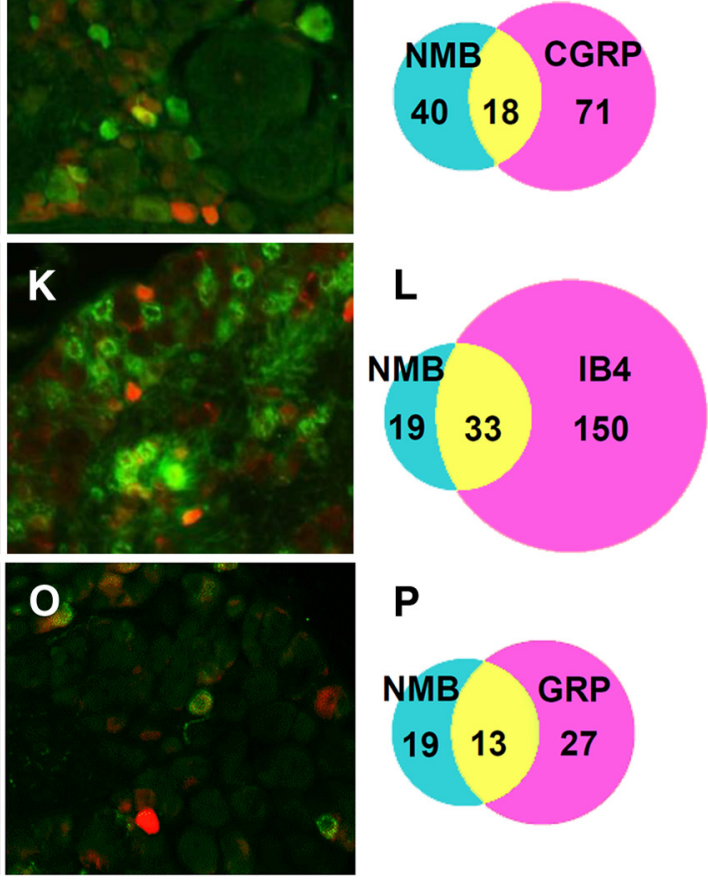

P

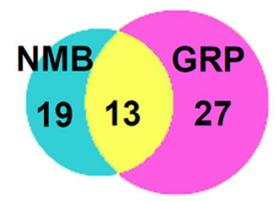

Figure 1. NMB expression in a subpopulation of DRG neurons. $A$, Rabbit anti-GFP IHC in DRGs of NMB-eGFP mice overlapped with Nmb ISH signals. High-power image of boxed area is shown in the right panel. Arrows indicate colocalized cells, and arrowheads indicate singly labeled cells. $\boldsymbol{B}$, Diagram to show the number of $\mathrm{Nmb}^{+}$and/or GFP ${ }^{+}$cells. $\boldsymbol{C}, \boldsymbol{D}$, (ross sections of lumbar DRGs from 2- and 8-week-old NMB-eGFP mice stained with chicken anti-GFP antibody $(\boldsymbol{C})$ showed that the percentage of eGFP ${ }^{+}$cells decreased significantly in adult stage $(\boldsymbol{D})$. Error bars represent SEM. $n=$ 4. ${ }^{* * *} p<0.001$, unpaired $t$ test. $\boldsymbol{E}-\boldsymbol{P}$, Double staining in lumbar DRGs of 8-week-old NMB-eGFP mice revealed that $31 \%$ (18 of 58 neurons), $63 \%$ ( 33 of 52 neurons), and $41 \%$ ( 13 of 32 neurons) of eGFP positive neurons (red) colocalized with 20\% (18 of 89 neurons) of CGRP ( $E, G$, green), $18 \%$ (33 of 183 neurons) of IB 4 binding ( $\boldsymbol{I}, \boldsymbol{K}$, green), and $33 \%$ ( 13 of 40 neurons) of GRP ( $\boldsymbol{M}, \boldsymbol{O}$, green) markers, respectively. Scale bars, $25 \mu \mathrm{m}$.

The neurokinin 1 receptor (NK1R) rabbit polyclonal antibody (1: 2000; AB5060, Millipore) was raised against residues 393-407 of the C terminus (Vigna et al., 1994). The specificity of this antibody was demonstrated by the absence of staining in knock-out mice (Catalani et al., 2006). The specificity of this antibody was also tested by preadsorption control experiments (Casini et al., 1997; 2004).

The GRP rabbit antiserum (1:500; catalog \#20073, Immunostar) was raised against bombesin, which shares a common amino acid sequence (WAVGHLM) with mouse GRP. The specificity of this antibody was con- firmed by the absence of staining in DRGs of Grp KO mice (Liu et al., 2009; Zhao et al., 2013), demonstrating that the anti-GRP antibody does not recognize other proteins. Preadsorption with GRP also resulted in a complete loss of immunofluorescence in mouse DRGs (Fleming et al., 2012).

Rabbit antiserum against Fluoro-Gold (FG; AB153, Millipore) was used at a concentration of 1:5000 (Bernstein et al., 2006). Control mice that did not receive injections of FG did not produce any immunostaining. FITC-conjugated IB4 (L2895, Sigma-Aldrich) was used at a concentration of $5 \mu \mathrm{g} / \mathrm{ml}$ (Reisfeld et al., 1967). 

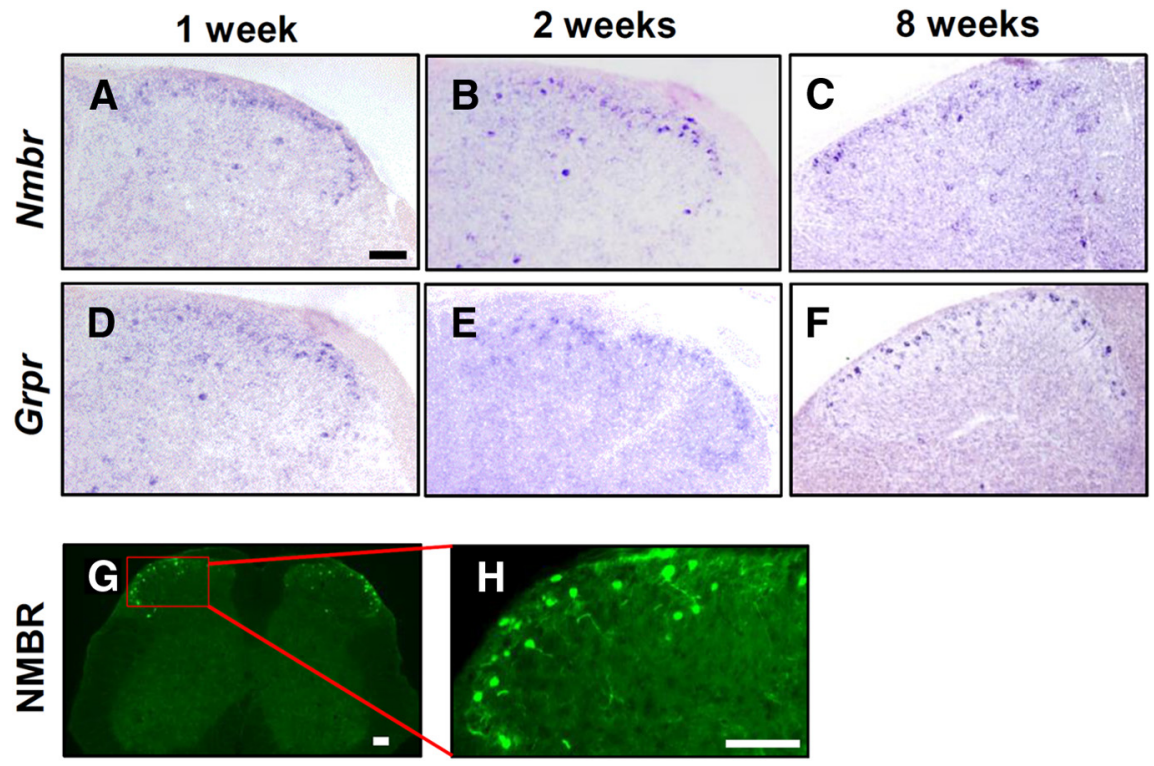

Figure 2. Nmbr and Grpr expression in the dorsal horn of the spinal cord. $\boldsymbol{A}-\boldsymbol{F}$, Expression of $\mathrm{Nmbr}(\boldsymbol{A}-\boldsymbol{C})$ and $\operatorname{Grpr}(\boldsymbol{D}-\boldsymbol{F})$ in lumbar spinal cord of 1-week-old (left), 2-week-old (middle), and 8-week-old (right) mice were detected by ISH. G, Cross section of L4 spinal cord from NMBR-eGFP mice stained with anti-GFP antibody indicated NMBR ${ }^{+}$cells (green). $\boldsymbol{H}$, High-power image of the boxed area in $\mathbf{G}$. Scale bars, $100 \mu \mathrm{m}$.

Retrograde tracing. A total of 32 adult NMBR-eGFP male mice were anesthetized with an intraperitoneal injection of a ketamine/xylazine cocktail and were fixed in a stereotaxic frame (Stoelting).

An incision was made along the midline of the skull, and a small hole was drilled through the bone over the approximate location of the injection sites. A pulled borosilicate glass pipette with a tip that was $20 \mu \mathrm{m}$ in diameter was backfilled with mineral oil and attached to a Nanoject II auto-nanoliter injector. The injector was attached to a manipulator and moved to the coordinates. A solution of $4 \% \mathrm{FG}$ (Biotium) was pulled into the pipette. FG $(0.15 \sim 0.25 \mu \mathrm{l})$ was injected into each injection site in different brain areas. For thalamus (ventral posterolateral thalamic nucleus; ventral posteromedial thalamic nucleus; posterior thalamic nuclear group; and posterior thalamic nuclear group, triangular part), 0.15 $\mu \mathrm{l}$ of FG was injected into site a [anteroposterior (AP), -0.94 ; mediolateral (ML), \pm 1.00 ; dorsoventral (DV), -3.45], $0.25 \mu$ l into site b (AP, -1.82 ; ML, $\pm 1.10 ; \mathrm{DV},-3.20$ ), and $0.15 \mu \mathrm{l}$ into site c (AP, -2.18 ; ML, \pm 1.25 ; DV,-3.25 ). For parabrachial nucleus (PBN; lateral PBN, medial PBN, superior cerebellar peduncle, and Kölliker-Fuse nucleus), $0.25 \mu \mathrm{l}$ of FG was injected into this site (AP, $-5.20 ; \mathrm{ML}, \pm 1.25 ; \mathrm{DV},-2.40$ ). For ventrolateral periaqueductal gray matter (VLPAG), $0.20 \mu \mathrm{l}$ of FG was injected into this site (AP, $-4.84 ; \mathrm{ML}, \pm 0.70 ; \mathrm{DV},-2.60)$. For lateral reticular nucleus (LRt), FG $(0.20 \mu \mathrm{l})$ was injected into this site (AP, -7.64 ; ML, $\pm 1.10 ; \mathrm{DV},-5.25)$. The stereotaxic coordinates were measured from bregma (AP) and the brain surface (DV). After the incision was sutured, the mouse was allowed to recover on a warm pad and was returned to the home cage upon walking. Recovered animals were not neurologically impaired. Mice were anesthetized $5 \sim 7 \mathrm{~d}$ later with an overdose of a ketamine/xylazine cocktail and perfused with $0.1 \mathrm{M}$ PBS and then $4 \%$ paraformaldehyde. The brain and spinal cord were removed, postfixed in $4 \%$ paraformaldehyde for $6 \mathrm{~h}$ at $4^{\circ} \mathrm{C}$, and cryoprotected overnight in $30 \%$ sucrose in PBS. Brains and spinal cords were sectioned transversely on a cryostat at 50 and $20 \mu \mathrm{m}$, respectively, for injection site observation or immunofluorescent staining.

$R T-P C R$. RT-PCR was performed as previously described (Liu et al., 2011). Briefly, spinal cords were dissected out from 9-week-old male mice ( $n=5$ per genotype). Total RNA was isolated, and genomic DNA was removed in accordance with the manufacturer's instructions (RNeasy Plus Mini Kit, Qiagen). Single-stranded cDNA was synthesized by using the High Capacity cDNA Reverse Transcription Kit (Life Technologies). Gene expression of Grpr and Nmbr was determined by realtime PCR (StepOnePlus, Applied Biosystems). Specific primers were designed with the National Center for Biotechnology Information Primer-BLAST. The fidelity and specificity of the primers was validated by real-time PCR using serial volume $(1,0.1$, and $0.01 \mu \mathrm{l}$ ) of wild-type spinal cord cDNA and PCR efficiency (Ef) was calculated. The following primers were used: $\operatorname{Grpr}$ (NM 008177.2, Ef $\left.=0.9583, R^{2}=0.9954\right): 5^{\prime}-\mathrm{TG}$ ATTCAGAGTGCCTACAATCTTC-3', 5'-CT TCCGGGATTCGATCTG-3'; amplicon size, $71 \mathrm{bp} ; \mathrm{Nmbr}$ (NM_008703.2, $\mathrm{Ef}=1.0466, R^{2}$ = 1): 5'-GGGGGTTTCTGTGTTCACTC-3', 5'-CATGGGGTTCACGATAGCTC-3'; amplicon size, 67 bp; Brs-3 (NM_009766.3): 5' GCACCCTGAACATACCGACT-3', 5' -AGAT GATTCGGCAACCAGCA-3'; amplicon size, $127 \mathrm{bp} ;$ Actb (NM_007393.3, Ef $=0.9987, R^{2}$ $=1$ ): 5' -TGTTACCAACTGGGACGACA-3', 5'-GGGGTGTTGAAGGTCTCAAA-3'; amplicon size, 166 bp; and Gapdh (NM_008084.2, $\left.\mathrm{Ef}=1.1212, R^{2}=0.9985\right): 5^{\prime}$-CCCAGCAAGG ACACTGAGCAA-3', 5' -TTATGGGGGTCTG GGATGGAAA-3'; amplicon size, 93 bp.

Real-time PCR was performed with FastStart Universal SYBR Green Master (Roche Applied Science). All samples $(0.1 \mu \mathrm{l})$ were assayed in duplicate. PCR (heating at $95^{\circ} \mathrm{C}$ for $10 \mathrm{~s}$ and at $60^{\circ} \mathrm{C}$ for $30 \mathrm{~s}$ ) were performed. Data were analyzed using the Comparative CT Method (StepOne Software version 2.2.2.), and the expression of target mRNA was normalized to the expression of Actb and Gapdh.

Radioligand binding assay. Stable HEK 293 cell lines expressing GRPR were generated as described previously (Liu et al., 2011). The cells were cultured in DMEM medium with $10 \%$ fetal bovine serum (Sigma), scraped from the flask, sonicated, and centrifuged. The supernatant was collected and recentrifuged at $18,000 \mathrm{rpm}$ for $1 \mathrm{~h}$ at $4^{\circ} \mathrm{C}$. The pellet was resuspended in ice-cold storage buffer, and protein concentrations were determined using the Pierce Non-Reducing Agent Compatible Kit. Briefly, $25 \mu \mathrm{g}$ of membrane protein was used in triplicate for each sample. After the addition of $25 \mu \mathrm{g}$ of membrane protein to each well, various concentrations of $\mathrm{NMB}$ ranging from 0 to $10 \mathrm{nM}$ were added in a solution volume of $10 \mu \mathrm{l}$ to triplicate wells. To each well, $\sim 0.1 \mathrm{~nm}$ ${ }^{125} \mathrm{I}$-GRP $(2200 \mathrm{Ci} / \mathrm{mmol}$; PerkinElmer $)$ in a solution volume of 100 $\mu \mathrm{l}$ of binding buffer was added. The plate was incubated at room temperature for $1 \mathrm{~h}$ and washed twice. The membranes were allowed to dry, were removed, and were placed in separate tubes for determination of bound radioactivity. The radioactivity was counted using a Packard II $\gamma$ counter (PerkinElmer), and the data were plotted in Prism 5 (GraphPad Software).

Data analysis. All values are expressed as the mean \pm SEM. Statistical analysis was performed using Prism version 5.03 (GraphPad Software). A $p$ value of $<0.05$ was considered statistically significant.

\section{Results}

\section{A majority of NMB is expressed in nonpeptidergic primary sensory neurons}

To characterize NMB expression in DRG neurons of mice, we took advantage of NMB-eGFP mice and performed ISH in DRG neurons using an $\mathrm{Nmb}$ in situ probe followed by IHC staining using anti-GFP antibody. We found that $91 \%$ of $\mathrm{eGFP}^{+}$cells ( 417 of 458 cells) and $85 \%$ of $N m b^{+}$cells ( 417 of 492 cells) were colocalized (Fig. $1 A, B$ ), indicating that the expression pattern of eGFP is largely consistent with that of $N m b$ in DRG neurons. Next we examined $N m b$ expression at different stages. The percentage of $\mathrm{eGFP}^{+}$neurons was $\sim 24 \%$ ( 445 of 1884 neurons) at 2 weeks (Fig. 1C). By 8 weeks of age, the percentage was reduced to 
$\sim 10 \%$ (217 of 2179 neurons; Fig. 1D), and this level was maintained up to 12 weeks (data not shown). Therefore, during the postnatal developmental stage, there is a progressive reduction of $\mathrm{NMB}$ expression in DRG neurons.

To characterize the molecular identity of $\mathrm{NMB}^{+}$neurons, we performed double IHC staining of eGFP with different molecular markers, including CGRP (a peptidergic marker), IB4 (a nonpeptidergic marker), and GRP using 8-week-old mice. Approximately $31 \%$ of $\mathrm{eGFP}^{+}$neurons (18 of 58 neurons) expressed CGRP (Fig. $1 E-H$ ), and $63 \%$ (33 of 52 neurons) were IB4 positive (Fig. 1I-L). Importantly, $\sim 33 \%$ of $\mathrm{GRP}^{+}$neurons [13 of 40 neurons; $8 \%$ of total DRG neurons (40 of 513)] overlapped with $41 \%$ of $\mathrm{eGFP}^{+}$ neurons (13 of 32 neurons; Fig. $1 M-P$ ). These results indicate that NMB and GRP expression overlaps in DRGs, with the former predominantly in nonpeptidergic neurons.

\section{Distinct expression of NMBR and GRPR in the dorsal spinal cord} We next used ISH and eGFP staining in NMBR-eGFP mice to examine the relationship between NMBR and GRPR expression in adult spinal cord. A majority of $\mathrm{Nmbr}^{+}$neurons were located in the superficial dorsal horn, with a few located in the deep dorsal horn of the spinal cord (Fig. 2A-C). The expression pattern is similar to that of $\operatorname{Grpr}$ (Fig. 2D-F). It is also consistent with eGFP immunostaining in NMBR-eGFP mice (Fig. 2G,H).

Double staining of eGFP and PKC $\gamma$, a marker for lamina IIi, clearly demonstrated that $\mathrm{NMBR}^{+}$neurons were mainly located in lamina I and II with a few $\mathrm{NMBR}^{+}$neurons detected in the area ventral to $\mathrm{PKC} \gamma$ (Fig. $3 A-C$ ). Notably, there was no overlap between NMBR and NK1R, a marker that labels the majority of lamina I projection neurons (Todd et al., 2000; Fig. 3D-F). Despite similar expression patterns of Nmbr and Grpr, only 14\% of $\mathrm{eGFP}^{+}$neurons (4 of 28 neurons) or $10 \%$ of $\mathrm{GRPR}^{+}$neurons (4 of 39 neurons) coexpressed the two receptors (Fig. 3G-I). In addition, a majority of $\mathrm{NMBR}^{+}$neurons (79\%; 187 of 237 neurons) are positive for Vglut2, a glutamatergic neuronal marker (Fremeau et al., 2001), whereas only $4 \%$ of $\mathrm{NMBR}^{+}$neurons (5 of 118 neurons) were positive for Gad67, an inhibitory neuronal marker (Fig. 3J,K). Similarly, GRPR ${ }^{+}$neurons labeled by rabbit anti-GRPR antibody largely expressed Vglut2 (77\%; 106 of 137 neurons), but not Gad67 (8\%; 11 of 130 neurons; Fig. $3 L, M)$. Thus, the majority of $\mathrm{NMBR}^{+}$and $\mathrm{GRPR}^{+}$neurons are likely to be excitatory interneurons.

$\mathbf{J}$
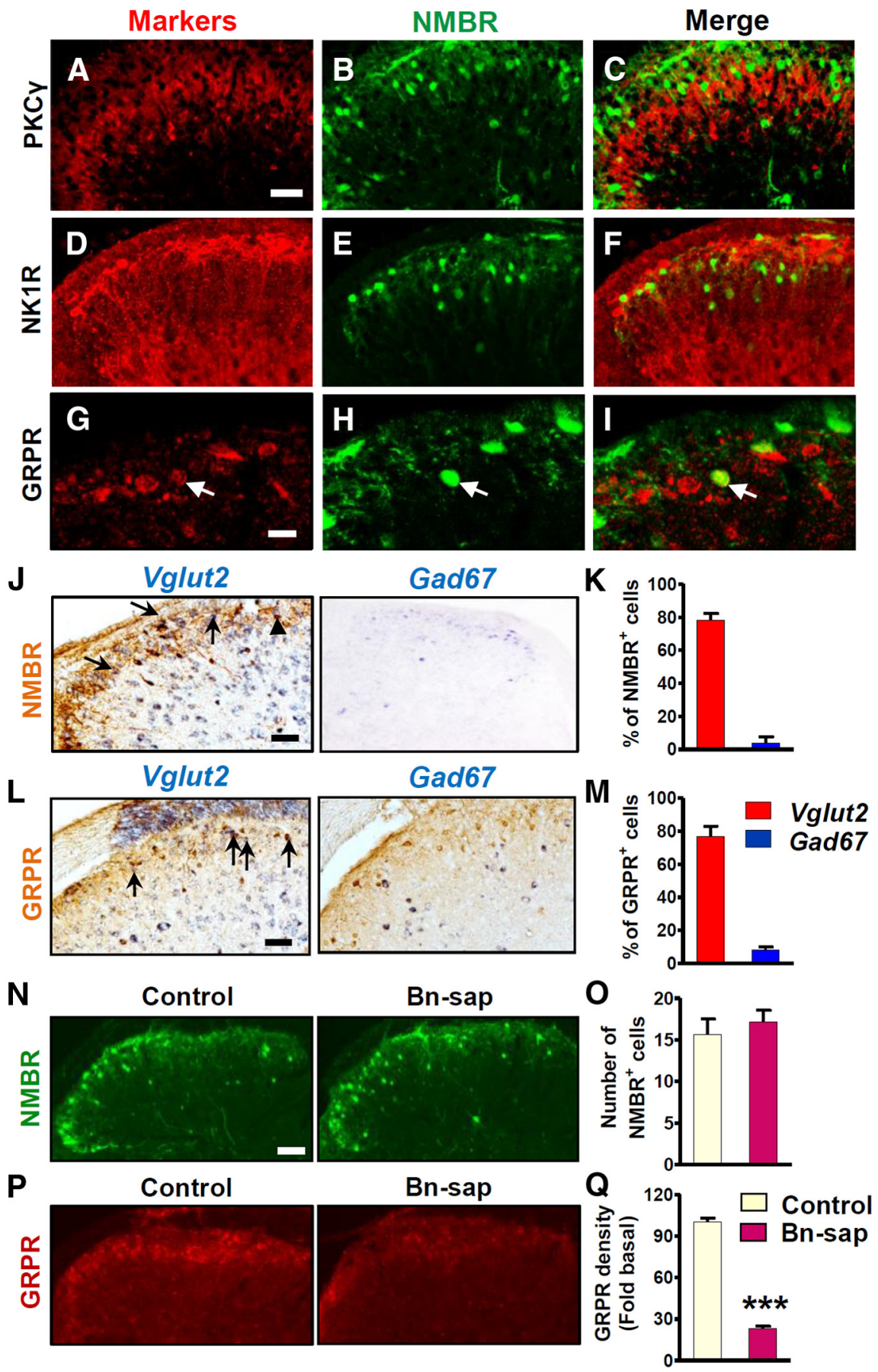

Figure 3. NMBR expression pattern in superficial dorsal horn neurons. A-C, Double IHC staining showed that eGFP-positive neurons (green) were located dorsal to PKC $\gamma($ red). D-F, There was no overlapping between eGFP (green) and NK1R (red). G-I, Double IHC showed that eGFP (green) and GRPR (red) were largely expressed in different populations. Arrows indicate double-labeled cells.J, NMBR neurons labeled by rabbit anti-GFP antibody (brown) colocalized with Vglut2 (blue in left column) but not Gad67 (blue in right column). Vglut2 and Gad67 were labeled by ISH. Arrows indicate double-labeled cells, and arrowheads indicate Vglut2 only. $K$, Quantified data showed that $79 \%$ of eGFP ${ }^{+}$cells (187 of 237 cells) are Vglut2 ${ }^{+}$and $4 \%$ ( 5 of 118 cells) are Gad $67^{+}$. L, M, GRPR ${ }^{+}$neurons were largely coexpressed with Vglut2 (77\%, 106 of 137 neurons), but not with Gad67 (8\%, 11 of 130 neurons). Arrows indicate double-labeled cells. N, eGFP staining (top row) in the lumbar spinal cord of NMBR-eGFP mice was comparable between the control and Bn-sap groups. $\mathbf{0}$, Quantified data showed that the number of $\mathrm{NMBR}^{+}$cells was not affected by Bn-sap. $P, \mathbf{Q}$, GRPR staining using rabbit anti-GRPR antibody in the superficial dorsal horn was mostly ablated by Bn-sap compared with control. The density of GRPR staining was significantly decreased in Bn-sap-treated mice. Error bars represent SEM. $n=3$ mice/group. ${ }^{* *} p<0.001$, unpaired $t$ test.

To further confirm that NMBR and GRPR are expressed in different populations, we treated NMBR-eGFP mice with intrathecal Bn-sap, which was shown to specifically ablate GRPR neurons due to the fact that NMBR could not internalize bomb- 
A Bregma $-0.94 \mathrm{~mm}$
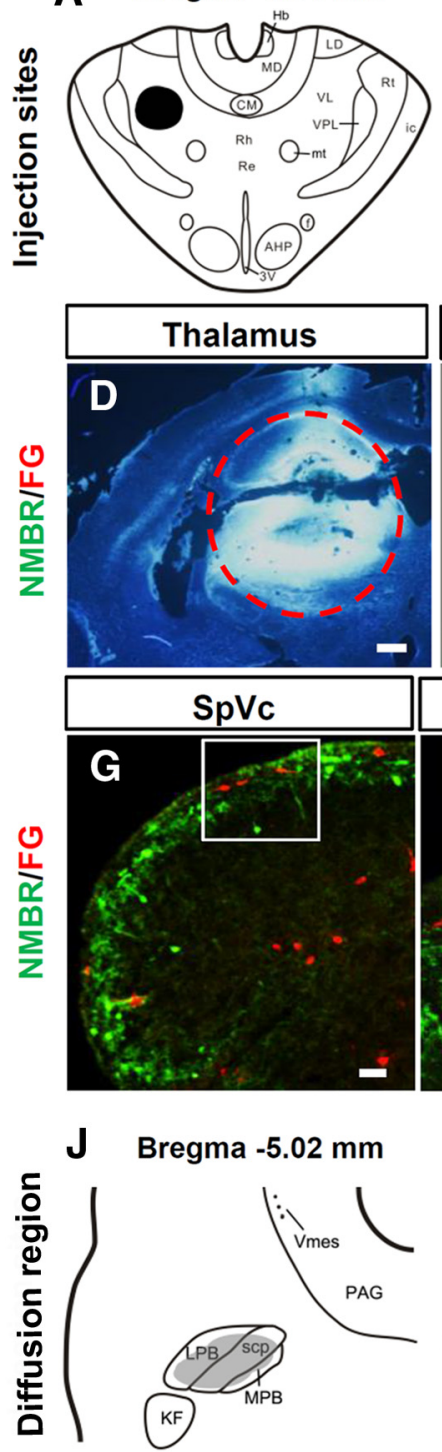

$\mathbf{K}$

B Bregma $-1.82 \mathrm{~mm}$
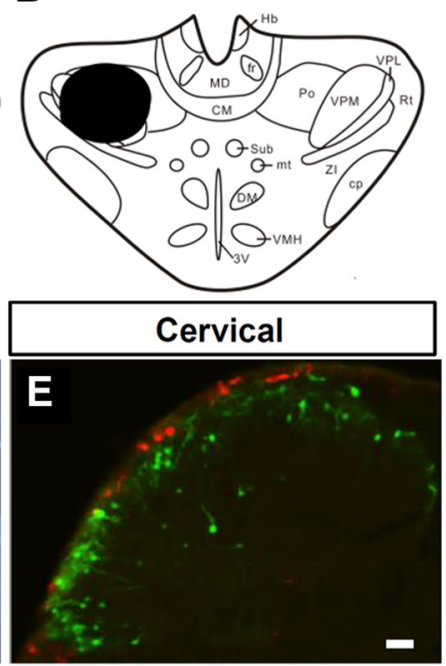

(4)

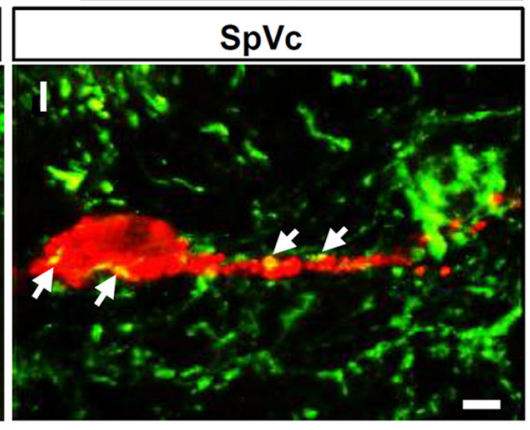

L Bregma $-5.52 \mathrm{~mm}$
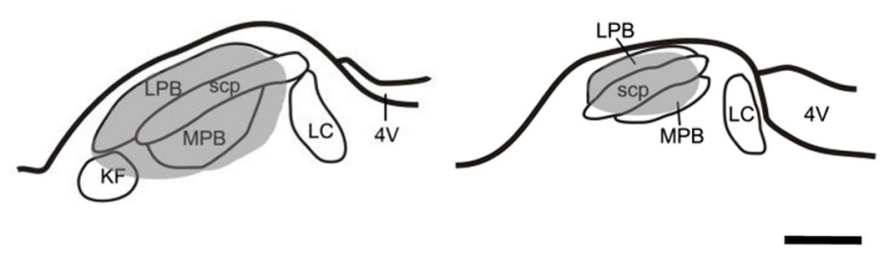
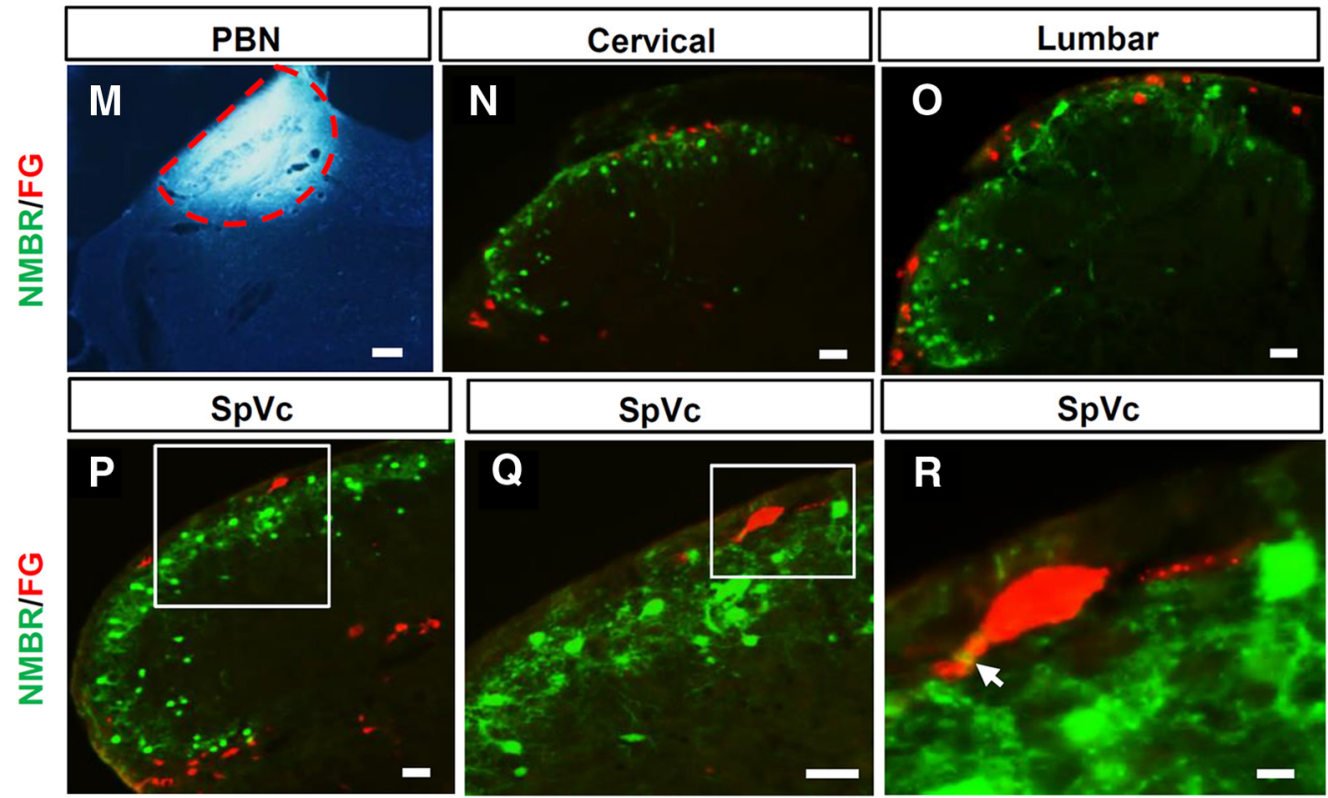

Figure 4. Retrograde tracing of $\mathrm{NMBR}^{+}$neurons in the spinal cord and SpVC. A-C, Diagrams show FG injection sites (blacked areas) in the thalamus. $\boldsymbol{D}$, The $\mathrm{FG}$ (bright white) injection site in the thalamus is indicated by a red dashed circle. $\boldsymbol{E}-\boldsymbol{H}$, There were no NMBR (GFP, green) and FG (red) double-labeled cells in the dorsal horn of the cervical (Figure legend continues.) 
esin, a prerequisite for saporin-based ablation (Sun et al., 2009). We found that the number of $\mathrm{eGFP}^{+}$neurons was not significantly reduced in Bn-sap group $\left(p=0.5442 ; F_{(8,7)}=1.845\right.$; Fig. $3 N, O)$, whereas GRPR ${ }^{+}$neurons labeled by mouse anti-GRPR antibody were largely ablated by Bn-sap $\left(p<0.001 ; F_{(12,8)}=\right.$ 5.558; Fig. 3P,Q). We previously showed that Bn-sap failed to further attenuate scratching behavior in Grpr KO mice (Sun et al., 2009). In line with this, the present results demonstrate that Bnsap only ablates $\mathrm{GRPR}^{+}$but not $\mathrm{NMBR}^{+}$neurons in the spinal cord.

\section{$\mathrm{NMBR}^{+}$neurons in the superficial dorsal horn and trigeminal nucleus caudalis are interneurons}

$\mathrm{NMBR}^{+}$neurons with dense fibers and terminals are mainly distributed in laminae I and II (Fig. 4, green). To determine whether $\mathrm{NMBR}^{+}$neurons are projection neurons or interneurons, FG was injected into the thalamus, PBN, PAG, or LRt for retrograde tracing of projection neurons followed by double IHC staining, as described previously (Li et al., 1996; Fig. 4A-D, J-M; the data on PAG and LRt not shown).

FG-labeled lamina I neurons were found predominantly in the trigeminal nucleus caudalis $(\mathrm{SpVc})$ and upper cervical segments of the spinal cord after FG injection into the thalamus (Fig. $4 E-H$, red), while after $\mathrm{PBN}$ injection, a majority of $\mathrm{FG}^{+}$neurons were found in lumbar segments (Fig. $4 N-Q$, red). About $75 \%$ of $\mathrm{FG}^{+}$neurons were located in the superficial dorsal horn contralateral to the injection site. In addition, $\mathrm{FG}^{+}$neurons were also found in the lateral cervical nuclei and lateral spinal nuclei (Fig. $4 E, F, N, Q)$. Of 300 sections examined from different segments of the spinal cords or SpVcs of mice $(n=15)$ that were injected with FG into thalamus, PBN, PAG, or LRt, none of the $\mathrm{NMBR}^{+}$neurons were colocalized with FG. However, we found that $\mathrm{NMBR}^{+}$ fibers closely contacted the projection neurons in lamina I of the SpVc (Fig. 4I,R) or the spinal dorsal horn. Together with previous studies (Wang et al., 2013) and the findings that $\mathrm{NMBR}^{+}$and $\mathrm{GRPR}^{+}$neurons are not colocalized with NK1R ${ }^{+}$neurons (the majority are projection neurons), these results indicate that both $\mathrm{NMBR}^{+}$and $\mathrm{GRPR}^{+}$neurons are interneurons.

\section{NMBR and GRPR concomitantly relay histaminergic itch} We next compared the time course of scratching behavior induced by intrathecal injection of $\mathrm{GRP}_{18-27}$ and NMB. GRP (1

\footnotetext{
$\leftarrow$

(Figure legend continued.) spinal cord $(\boldsymbol{E})$, lumbar spinal cord $(\boldsymbol{F})$, and $\operatorname{SpV}(\boldsymbol{G}, \boldsymbol{H})$ in NMBR-eGFP mice. $\boldsymbol{H}$, High-power image of the boxed area in $\boldsymbol{G}$. $\boldsymbol{I}$, High-power image of the boxed area in $\boldsymbol{H}$ showing that $\mathrm{NMBR}^{+}$terminals (yellow) contact $\mathrm{FG}^{+}$spinothalamic tract neurons. Arrows indicate contact sites. $J-L$, The shaded area indicates the diffused region of $F G$ after PBN injection. $\boldsymbol{M}$, Red dashed line defines the border of the injection site of FG in PBN. $\boldsymbol{N}-\mathbf{Q}$, Double staining in the dorsal horns of cervical spinal cord $(\boldsymbol{N})$, lumbar spinal $\operatorname{cord}(\boldsymbol{O})$, and $\operatorname{SpVc}(\boldsymbol{P}, \mathbf{Q})$ in NMBR-eGFP mice showed that NMBR ${ }^{+}$(GFP, green) neurons were not $\mathrm{FG}^{+}$(red) projection neurons to PBN. $\boldsymbol{Q}$, High-power image of the boxed area in $\boldsymbol{P}$. $\boldsymbol{R}$, High-power image of the boxed area in $\mathbf{Q}$ showing that $\mathrm{NMBR}^{+}$terminals made close contacts (yellow) with $\mathrm{FG}^{+}{ }^{+} \mathrm{PBN}$ projection neurons. Arrows indicate contact sites. Scale bars: $\mathbf{A}-\mathbf{D}, \mathbf{J}-\mathbf{M}, 400 \mu \mathrm{m} ; \mathbf{E}-\mathbf{H}, \mathbf{N}-\mathbf{Q}, 40 \mu \mathrm{m}$; $I, R, 10 \mu \mathrm{m} .3 \mathrm{~V}$, Third ventricle; $4 \mathrm{~V}$, fourth ventricle; AHP, anterior hypothalamic area, posterior; $C M$, central medial thalamic nucleus; $c p$, cerebral peduncle, basal part; DM, dorsalmedial nucleus; $\mathrm{f}$, fornix; fr, fasciculus retroflexus; $\mathrm{Hb}$, habenular nucleus; ic, internal capsule; KF, KöllikerFuse nucleus; LC, lateral cervical nucleus; LD, laterodorsal thalamic nucleus; LH, lateral hypothalamic nucleus; LPB, lateral PBN; MD, mediodorsal thalamic nucleus; MPB, medial PBN; $\mathrm{mt}$, mammillothalamic tract; $\mathrm{PF}$, parafascicular thalamic nucleus; $\mathrm{Po}$, posterior thalamic nuclear group; Re, reuniens thalamic nucleus; Rh, rhomboid thalamic nucleus; Rt, reticular thalamic nucleus; scp, superior cerebellar peduncle; Sth, subthalamic nucleus; Sub, submedius thalamic nucleus; VL, ventrolateral thalamic nucleus; VMH, ventrolmedial hypothalamic nucleus; Vms, trigeminal mesencephalic nucleus; VPL, ventral posterolateral thalamic nucleus; VPM, ventral posteromedial thalamic nucleus; Zl, zone incerta.
}

nmol) induced robust bilateral scratching behavior ( $>15$ bouts $/ 5$ $\mathrm{min}$ ), which declined gradually and lasted as long as $30 \mathrm{~min}$ (Fig. $5 A)$. By contrast, scratching responses induced by NMB (1 nmol) decayed rapidly within $10 \mathrm{~min}$ and were almost absent after 15 min (Fig. 5A), which is in agreement with previous studies (Bishop et al., 1986). To identify the target tissue of intrathecal $\mathrm{NMB}$ and GRP, TRPV ${ }^{+}$primary afferents were ablated via intrathecal injection of RTX, a potent TRPV1 agonist. The success of fiber ablation was indicated by attenuated neurogenic pain induced by intraplantar injection of capsaicin $\left(p=0.0226, F_{(5,5)}\right.$ $=49$; Fig. $5 B$ ) and by a lack of TRPV ${ }^{+}$staining in the spinal cord of RTX-treated mice (Fig. 5C). Indeed, RTX treatment had no effect on the scratching behavior induced by intrathecal NMB $\left(p=0.4237, F_{(5,7)}=2.749\right)$ or GRP $\left(p=0.2716, F_{(5,5)}=1.438\right.$; Fig. $5 D)$, demonstrating that it is the spinal NMBR and GRPR that mediated the scratching evoked by intrathecal NMB and GRP.

To determine whether BRS-3, the third mammalian bombesin receptor, might mediate bombesin peptides-induced itch, we examined the scratching response of Grpr/Nmbr double knockouts (thereafter referred to as DKO). Importantly, scratching behaviors elicited by intrathecal injection of GRP (1 nmol), NMB (1 nmol), or Bn $(0.05 \mathrm{nmol})$ were all abolished in DKO mice (Fig. 5E). Consistently, Brs-3 mRNA was not detectable in the spinal cord (Fig. 5F). These results demonstrate that the actions of intrathecal NMB, GRP, and bombesin are exclusively mediated by NMBR and GRPR in the spinal cord.

To assess the role of NMBR in itch transmission, we examined the scratching behavior of $\mathrm{Nmbr}^{-1-}$ mice after intradermal injection of a number of histamine-dependent pruritogens (i.e., histamine, compound 48/80, and 5-HT) as well as histamineindependent pruritogens (i.e., CQ and BAM8-22, two ligands for MRGPRA3 and MRGPRC11, respectively; Liu et al., 2009). Surprisingly, $\mathrm{Nmbr}^{-1-}$ mice and WT littermates exhibited comparable scratching responses to all of the drugs tested (histamine: $p=0.5532, F_{(5,5)}=1.640$; compound 48/80: $p=0.1233, F_{(6,6)}=$ 1.008 ; 5 -HT: $p=0.3553, F_{(6,6)}=1.134$; CQ: $p=0.9866, F_{(5,5)}=$ 1.140; BAM8-22: $p=0.8759, F_{(5,5)}=1.177$; Fig. $\left.5 G\right)$. We then compared the scratching behavior between DKO and Grpr KO mice. Consistent with our previous results (Sun and Chen, 2007; Sun et al., 2009), Grpr KO mice showed statistically insignificant reduction of histamine-dependent scratching behavior (Fig. $5 H)$, whereas histamine-independent itch was markedly reduced (Fig. 5I). DKO mice showed significantly attenuated responses to histaminergic pruritogens compared with WT and Grpr KO mice (Fig. $5 H$ ) without further reduction in response to BAM8-22 or CQ compared with Grpr KO mice (Fig. 5I). These data reveal that NMBR and GRPR concomitantly relay histaminergic itch transmission, whereas NMBR is dispensable for acute nonhistaminergic itch.

\section{Enhanced GRPR or NMBR signaling and lack of compensatory change of receptor expression in $\mathrm{Nmbr}$ or $\mathrm{Grpr}$ KO mice \\ Normal histaminergic itch of Nmbr and Grpr KO mice prompted} us to postulate that GRPR and NMBR signaling might be enhanced in Nmbr and Grpr KO mice, respectively. The expression of GRPR and NMBR in the spinal cord and the scratching responses evoked by intrathecal injection of agonists enabled us to quantitatively measure the activity of the receptor directly. We compared intrathecal GRP-induced scratching behavior between WT mice and $\mathrm{Nmbr}^{-1-}$ mice, which are devoid of potential GRP-NMBR interactions resulting from low-affinity binding. 
A

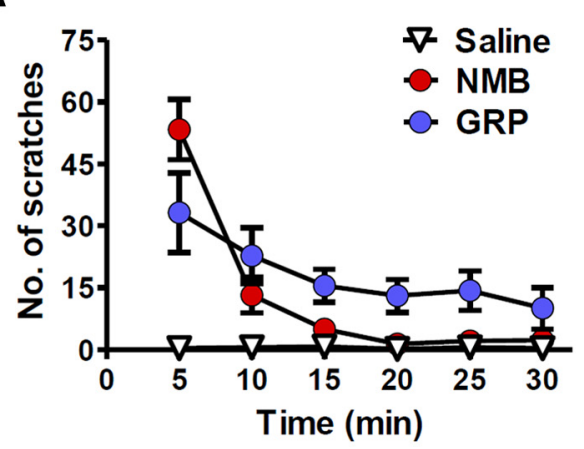

B

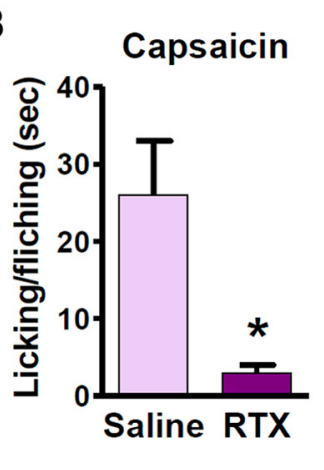

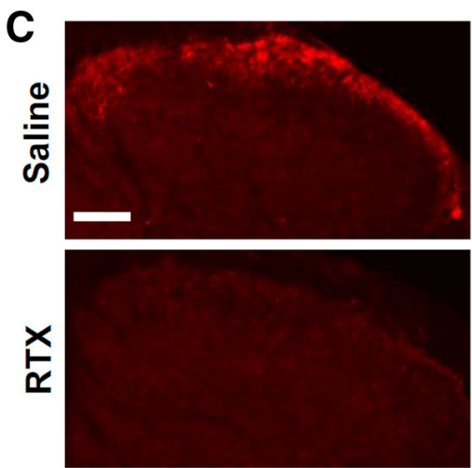

F

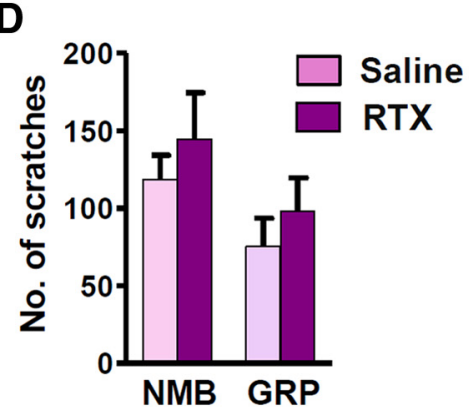

E

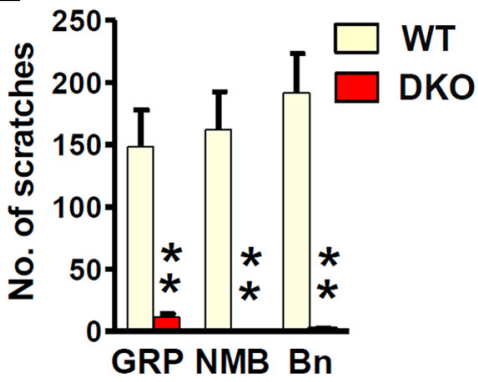

Tha SC $\Delta R T$

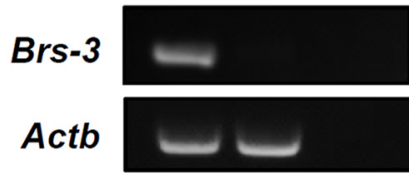

G

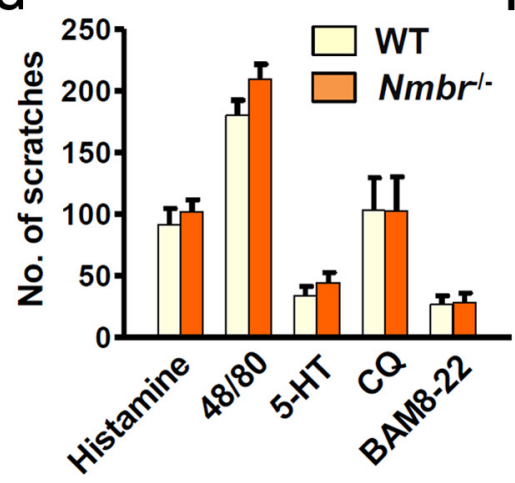

H

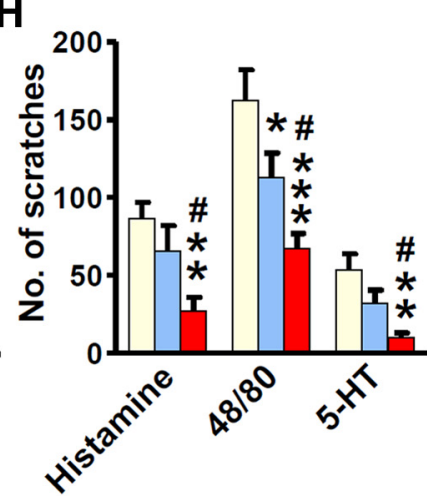

I

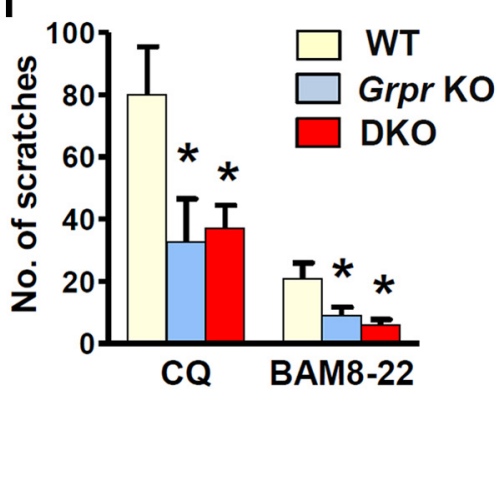

Figure 5. Deficits of acute itch in Grpr/Nmbr double KO mice. $A$, Intrathecal injection of NMB (1 nmol) and GRP (1 nmol) evoked robust scratching behavior. $B$, Licking and flinching behavior induced by capsaicin ( $2 \mu \mathrm{g}$, i.pl.) was significantly reduced in RTX-treated mice. C, Ablation of TRPV1 ${ }^{+}$fibers in the RTX group (bottom) was confirmed by TRPV1 immunostaining (red). Scale bar, $100 \mu \mathrm{m}$. D, Scratching behavior elicited by intrathecal NMB or GRP was not affected by RTX treatment ( $25 \mathrm{ng}$, i.t.). E, Scratching behavior induced by GRP ( $1 \mathrm{nmol}), \mathrm{NMB}(1 \mathrm{nmol})$, and Bn ( $0.05 \mathrm{nmol})$ was abolished in DKO mice compared with WT littermates. $\boldsymbol{F}$, Brs-3 mRNA was detected in the thalamus (Tha), but not in the spinal cord (SC). Actb was used as internal control to show equal loadings. The absence of Brs-3 and $A c t b$ bands in thalamus samples when reverse transcriptase was omitted ( $\triangle$ RT) indicated that the reactions were specific. G, Nmbr ${ }^{-1-}$ mice and WT littermates showed comparable scratching behavior in response to the injection of histamine ( $500 \mu \mathrm{g}$, i.d.), compound $48 / 80$ (100 $\mu \mathrm{g}), 5-\mathrm{HT}$ ( $50 \mathrm{nmol}), \mathrm{CQ}(200 \mu \mathrm{g})$, and BAM8-22 (150 $\mu \mathrm{g})$. H, Compared with WT littermates Grpr K0 mice showed moderate but significant reduction in scratching behavior evoked by intradermal injection of compound 48/80, but not histamine or 5 -HT, while DKO mice showed a deficit in all tested models compared with both WT and Grpr KO mice. I, Grpr KO mice showed a deficit in CQ and BAM8-22 models. There is no further reduction in DKO mice of CQ- or BAM8-22-induced scratching behavior compared with Grpr KO mice. Error bars represent SEM. $n=5-15$ mice/group. ${ }^{*} p<0.05,{ }^{* *} p<0.01$, ${ }^{* * *} p<0.001$, versus WT or saline-treated mice $(\boldsymbol{B})$. $\# p<0.05$, versus Grpr KO mice. Unpaired $t$ test $(\boldsymbol{B}, \boldsymbol{D}, \boldsymbol{E}, \boldsymbol{G})$, one-way ANOVA followed by Newman-Keuls test $(\boldsymbol{H}, \boldsymbol{I})$.

Indeed, $\mathrm{Nmbr}^{-1-}$ mice showed enhanced response to GRP (1 nmol, i.t.) relative to WT mice (Fig. 6A). Similarly, Grpr KO mice also showed enhanced response to NMB (1 nmol, i.t.; Fig. 6B). We used the dose of $1 \mathrm{nmol}$ for GRP or NMB because at this dose the number of scratching bouts evoked has nearly reached a ceiling effect (Sun and Chen, 2007). One simple explanation is that the enhanced signaling might be a result of compensatory upregulation of Grpr in $\mathrm{Nmbr}^{-1-}$ mice or Nmbr in Grpr KO mice. To test this, we examined the mRNA level of $\mathrm{Grpr}$ and $\mathrm{Nmbr}$ using real-time RT-PCR. Surprisingly, Grpr expression in the spinal cord of $\mathrm{Nmbr}^{-/-}$mice did not differ from that of WT mice, nor did Nmbr expression in the spinal cord of Grpr KO mice (Fig. $6 C)$. Thus, it is unlikely that compensatory upregulation of the receptor expression would occur in these mutant mice.

\section{NMB exclusively signals through NMBR}

Next, we postulated that increased binding of GRP to GRPR and NMB to NMBR might account for apparent enhanced signaling of GRPR in $\mathrm{Nmbr}^{-1-}$ mice and NMBR in Grpr KO mice, respectively. Because GRP can bind to NMBR with a low affinity, we reasoned that the total number of scratching bouts elicited by intrathecal injection of GRP in WT mice should reflect a combined effect of GRP-GRPR and GRP-NMBR interactions. To determine whether the cross-binding between NMB and GRPR or GRP and NMBR could have an effect on scratching behavior, we first examined intrathecal NMB-elicited scratching bouts in $\mathrm{Nmbr}^{-/-}$mice on the basis of the premise that the sum of scratching behavior should reflect NMB-GRPR cross-signaling. Unexpectedly, intrathecal NMB failed to induce scratching behavior in $\mathrm{Nmbr}^{-/-}$ 
A

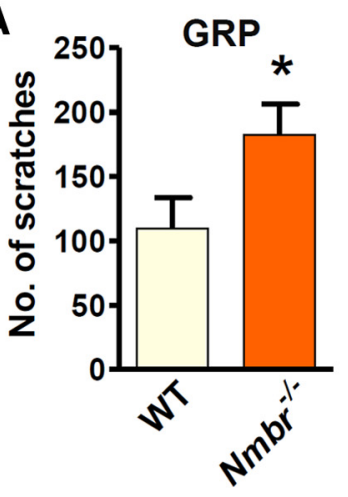

D

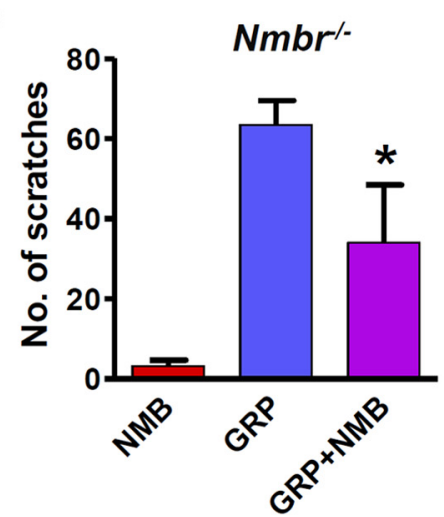

B

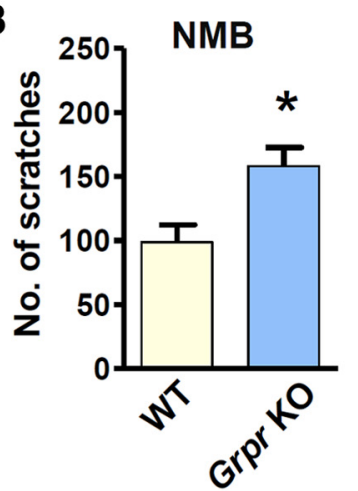

E

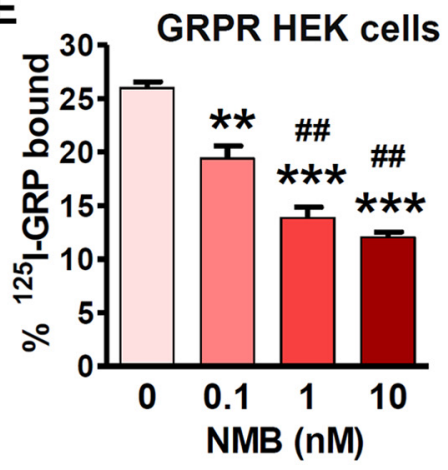

C
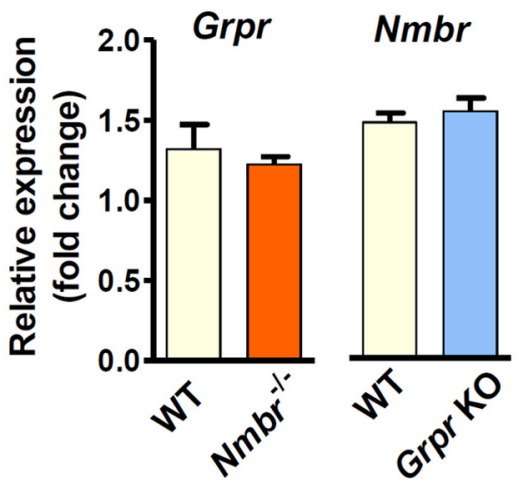

$\mathbf{F}$

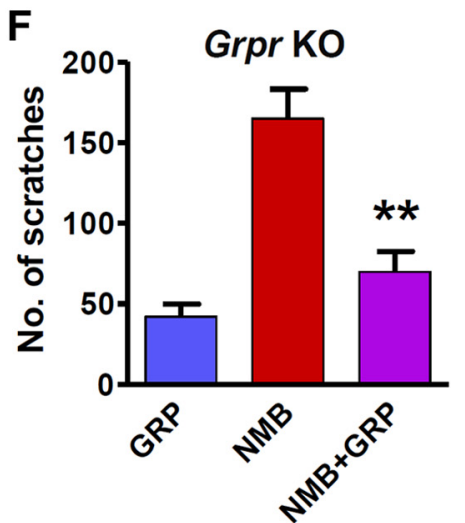

Figure 6. Cross-inhibition of GRP-GRPR and NMB-NMBR signaling. $\boldsymbol{A}, \mathrm{Nmbr}^{-1}$ - mice showed enhanced scratching response after intrathecal injection of GRP (1 nmol). $n=7$ mice/genotype. $\boldsymbol{B}$, Grpr KO mice showed enhanced scratching response to NMB (1 nmol). $n=8-9$ mice/genotype. $\boldsymbol{C}$, The level of Grpr mRNA was not changed in the spinal cord of Nmbr ${ }^{-/-}$mice, and the spinal Nmbr expression was not changed in Grpr KO mice. $n=5$ mice/group. D, Nmbr ${ }^{-1-}$ mice lost response to NMB (1 nmol, i.t.), while coinjection of NMB blocked GRP (0.1 nmol)-induced scratching behavior. $n=6$ mice/group. $E$, NMB dose-dependently attenuated the binding of ${ }^{125}$ I-GRP to GRPR, as revealed by competitive binding of ${ }^{125}$ I-GRP to GRPR-HEK293 cell membrane preparations. $n=3 /$ dose. $F$, In Grpr KO mice, intrathecal GRP injection ( $0.1 \mathrm{nmol})$ evoked a weak scratching response, and GRP significantly attenuated NMB (1 nmol)-induced scratching behavior. $n=6-12$ mice/group. Error bars represent SEM. ${ }^{*} p<0.05,{ }^{* *} p<0.01,{ }^{* * *} p<0.001$, versus WT $(\boldsymbol{A}-\boldsymbol{C})$, versus GRP (D), versus NMB $(\boldsymbol{F})$, versus NMB 0 nm $(\boldsymbol{E})$. \#\#p $<0.01$ versus NMB 0.1 nm. Unpaired $t$ test $(\boldsymbol{A}-\boldsymbol{C})$, one-way ANOVA followed by Newman-Keuls test $(\boldsymbol{D}-\boldsymbol{F})$.

mice (Fig. 6D). This finding demonstrates that NMB relays itch information exclusively through NMBR and a possible NMB-GRPR binding fails to produce a functional output.

The finding that $\mathrm{NMB}$ in $\mathrm{Nmbr}^{-1-}$ mice failed to produce an itch output suggests that NMB is unlikely to be a partial agonist for GRPR in the spinal cord. Rather, it raised the possibility that NMB might act as a functional antagonist for GRPR to impair normal GRP-GRPR signaling by noncognate NMB-GRPR binding in WT mice. To test the idea that NMB is an antagonist for GRPR, we reasoned that a coinjection of a high dose of NMB (1 nmol; hereafter referred as $\left.\mathrm{NMB}^{\mathrm{H}}\right)$ and a low dose of GRP $(0.1$ nmol; hereafter referred as $\mathrm{GRP}^{\mathrm{L}}$ ) might maximize the effect of NMB-mediated inhibition of GRP-GRPR signaling in $\mathrm{Nmbr}^{-/-}$ mice, in which a high concentration of NMB may be sufficient to compete with a low concentration of GRP for GRPR binding. As expected, $\mathrm{GRP}^{\mathrm{L}}$ alone induced a relatively modest scratching response $(\sim 60)$ in $\mathrm{Nmbr}^{-1-}$ mice (Fig. $\left.6 D\right)$. However, coinjection of $\mathrm{GRP}^{\mathrm{L}}$ and $\mathrm{NMB}^{\mathrm{H}}$ markedly inhibited scratching response relative to $\mathrm{GRP}^{\mathrm{L}}$ alone (Fig. $6 D$ ).

Next, we examined whether NMB could inhibit GRP binding to GRPR by performing a competitive radioligand binding assay using GRPR-HEK293 cell membrane preparation. The ability of $\mathrm{NMB}$ to inhibit the binding of ${ }^{125} \mathrm{I}-\mathrm{GRP}$ to GRPR in GRPRHEK293 cell membrane preparations is shown in Figure 6E. The amount of ${ }^{125} \mathrm{I}$-GRP bound in the absence of NMB was $26.0 \pm$ $1.0 \%$. The addition of $0.1 \mathrm{nM}$ NMB significantly inhibited binding to $19.4 \pm 2.0 \%(p<0.01)$. Binding was inhibited to $13.9 \pm$
$1.4 \%$ and $12.1 \pm 0.9 \%$ after the addition of 1 and $10 \mathrm{~nm} \mathrm{NMB}$, respectively. These values were significantly lower than binding in the presence of $0.1 \mathrm{nM}$ NMB $(p<0.01)$. Thus, these binding studies indicate that $\mathrm{NMB}$ can competitively inhibit the binding of GRP to GRPR. Together, our studies suggest that NMB is able to inhibit GRP-GRPR signaling through its competitive binding to GRPR and thereby limits the access of GRPR to GRP.

\section{GRP weakly activates NMBR}

In contrast to $\mathrm{NMB}, \mathrm{GRP}^{\mathrm{L}}$ induced a modest scratching response in $\operatorname{Grpr} \mathrm{KO}$ mice ( $42 \pm 8$ in $30 \mathrm{~min}$; Fig. $6 \mathrm{~F}$ ), supporting the idea that GRP may function as a partial agonist for NMBR. To further examine the seemingly "inhibitory" effect of GRP on NMBR, we used GRP ${ }^{\mathrm{L}}$ to avoid a possible masking effect of a high dose of GRP, which may overwhelm NMBR in Grpr KO mice. While intrathecal $\mathrm{NMB}^{\mathrm{H}}$ evoked robust scratching as expected in $\mathrm{Grpr}$ $\mathrm{KO}$ mice, there was a marked decrease of scratching elicited by a coinjection of $\mathrm{NMB}^{\mathrm{H}}$ and $\mathrm{GRP}^{\mathrm{L}}$ (Fig. $6 F$ ). This suggests that, despite a low concentration, GRP is still capable of attenuating cognate NMB-NMBR-mediated itch signaling.

\section{Spinal GRPR ${ }^{+}$neurons integrate NMBR-mediated itch signaling}

In contrast to spinal $\mathrm{NMBR}^{+}$neurons, which are dispensable for histamine-evoked itch (Mishra et al., 2012), GRPR ${ }^{+}$neurons in the spinal cord are critical for both histaminergic and nonhistaminergic itch. These findings raise an interesting possibility that 
A
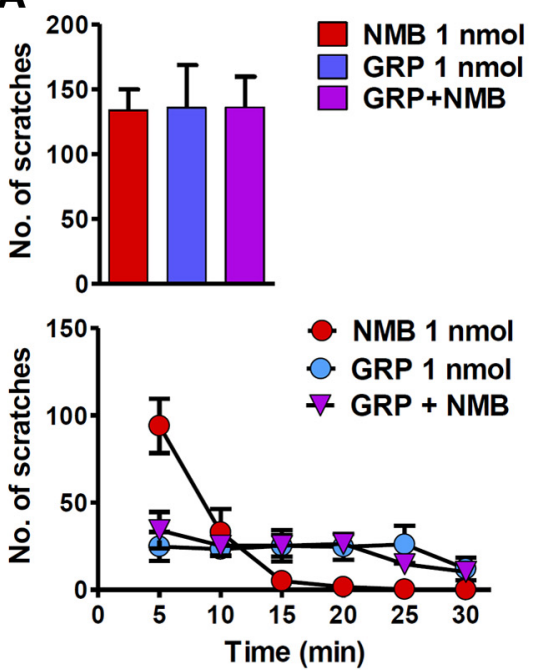

C

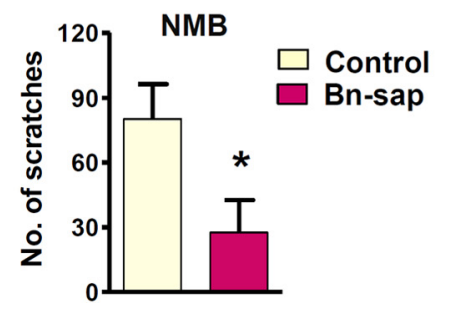

Figure 7. Masking effect of GRP on NMB-evoked scratching behavior in WT mice. $A, B$, Total scratching numbers (top row) and time course curves (bottom row) indicate that coinjection of GRP and NMB at equivalent doses masks the effect of NMB in WT mice. C, Bn-sap treatment significantly attenuated scratching behavior induced by intrathecal NMB $(0.3 \mathrm{nmol})$ compared with control treatment. Error bars represent SEM. $n=6$ mice/group.

in addition to GRP-encoded information, spinal GRPR ${ }^{+}$neurons receive and integrate histaminergic itch information carried by NMB-NMBR signaling. If so, this would place GRPR ${ }^{+}$neurons downstream of $\mathrm{NMBR}^{+}$neurons at the circuit level. Moreover, despite cross-inhibition of NMBR and GRPR signaling, the final output of itch information should be determined by $\mathrm{GRPR}^{+}$neurons instead of $\mathrm{NMBR}^{+}$neurons. To test this possibility, we compared scratching behavior between mice evoked by coinjection of NMB and GRP using a concentration that is likely to reach a maximal effect for each agonist $(1 \mathrm{nmol}$; Sun and Chen, 2007) and those evoked by GRP or NMB alone (Fig. 7A). Strikingly, we did not observe an additive effect as the total number of scratching responses evoked by the two peptides is similar to those evoked by GRP or NMB alone (Fig. 7A). Importantly, an analysis of time course curves revealed that NMB-NMBR activity was completely masked by GRP-GRPR activity (Fig. 7A). Consistently, no additive effect was detected when GRP and NMB were coinjected at a lower concentration (Fig. 7B). Furthermore, we found that intrathecal NMB-induced scratching behavior was also significantly reduced after $\mathrm{Bn}$-sap treatment (Fig. 7C). These results suggest that signals from NMB-NMBR and GRP-GRPR converge at $\mathrm{GRPR}^{+}$neurons, and only the latter function as an indispensable "gate" for histaminergic itch information.

\section{Discussion}

Our studies for the first time delineate the respective contribution of NMBR and GRPR to histamine-dependent and histamine-independent itch transmission. The largely nonoverlapping but neighboring expression of GRPR and NMBR in lam- inae I and II of the spinal cord and potential cross-binding of GRP to NMBR or of NMB to GRPR highlight the difficulty in delineating the roles of NMBR and GRPR in itch transmission. While either receptor is dispensable for histaminergic itch transmission, $\mathrm{Nmbr} / \mathrm{Grpr} \mathrm{DKO}$ mice exhibit deficits in histaminergic itch. This compensatory signaling cannot be attributed to an upregulation of expression of either receptor in the absence of the other. Using the scratching behavior of single mutants and WT mice to monitor the output of the receptor activity, we identified enhanced GRP-GRPR signaling in $\mathrm{Nmbr}^{-1-}$ mice or enhanced NMB-NMBR signaling in Grpr KO mice, which could account for a seemingly compensatory change. Because GRP is able to bind to NMBR, but preferentially binds to GRPR, it is conceivable that more GRP acts on GRPRs in $\mathrm{Nmbr}^{-/-}$mice than in WT mice and thus potentiates GRPGRPR signaling. Conversely, enhanced scratching responsiveness of Grpr KO mice to intrathecal NMB suggests that NMBNMBR signaling is strengthened due to the lack of divergence of NMB to GRPR.

Some controversies about GRP expression in DRGs were brought up due to the difficulties in detecting Grp mRNA by ISH (Fleming et al., 2012; Mishra and Hoon, 2013). However, the number of neurons expressing Grp mRNA and GRP protein was consistently found to be $\sim 8 \%$ and upregulated in DRG neurons, spinal primary afferents, and cutaneous nerve fibers in chronic itch conditions using IHC, ISH, or quantitative real-time PCR (Lagerström et al., 2010; Kagami et al., 2013; Nattkemper et al., 2013; Zhao et al., 2013; Liu et al., 2014; Takanami et al., 2014). Importantly, GRP immunostaining was completely lost in Grp KO mice (Liu et al., 2009; Zhao et al., 2013), demonstrating that the antiGRP antibody does not recognize other proteins. However, some reported either widespread staining (Liu et al., 2012) or slight staining of GRP (Fleming et al., 2012) in DRGs using the same anti-GRP antibody. These discrepancies can be explained by various experimental procedures used in different studies, as is often seen in the literature even though a specific antibody is used. The present studies provide further evidence supporting a functional role of GRP in DRGs, together with NMB, in relaying pruriceptive information from the periphery to the spinal cord.

A key finding of the present work is that NMB acts as a functional antagonist for GRPR in the spinal cord. This is unexpected, as NMB has long been considered as an agonist for GRPR (OhkiHamazaki, 2000). On the other hand, we confirm that GRP is a partial agonist for NMBR. In contrast to single mutants, whereby a higher concentration of GRP or NMB may preclude or attenuate noncognate peptide receptor signaling as a result of lack of divergence, the presence of both receptors in WT mice should permit more competitive binding of the receptor by a noncognate peptide. A competition of NMB with GRP for GRPR binding would result in attenuation of the total output of GRP-GRPR signaling (Fig. 8A). Similarly, in Grpr KO mice, GRP competes with NMB for NMBR binding and GRP-NMBR cross talk in- 
duces itch signaling at a diminished level. The net effect is an attenuation of NMBNMBR signaling. These findings imply distinct mechanisms underlying the mutual inhibition of the NMB-NMBR and GRP-GRPR signaling pathways when both NMB and GRP are presumably released into the spinal cord upon pruriceptive stimuli.

Using RC-3095 and PD168368 antagonist approaches, it has been concluded that bombesin does not act through GRPR/NMBR, and that GRPR and NMBR are independent pathways in the spinal cord (Su and Ko, 2011; Sukhtankar and Ko, 2013). However, RC-3096 and PD168368 are selective but not specific antagonists because they can also crossinhibit NMB or GRP binding to their cognate receptors (Kroog et al., 1995; Moody et al., 2003; Jensen et al., 2008). Moreover, intrathecal GRP-induced scratching bouts reflect a sum of GRPR and NMBR activation. These confounding variables make it difficult to delineate the respective roles of GRPR and NMBR in behavioral responses with pharmacological approaches. The finding that Bn-sap can selectively ablate $\mathrm{GRPR}^{+}$neurons demonstrates that bombesin binds spinal GRPR (Sun et al., 2009). The reason that $\mathrm{NMBR}^{+}$neurons remain intact in mice treated with Bn-sap is because Bn-sap that binds NMBR cannot be internalized, a premise for toxin-induced neuronal cell death (Wiley and Kline, 2000; Sun et al., 2009). In mammals, only three known receptors (GRPR, NMBR, and BRS-3) may mediate bombesin-induced scratching. The present study demonstrates that GRPR and NMBR are the only two principal receptors required for intrathecal bombesin-, GRP-, and NMB-induced scratching behavior, and they do not function independent of each other. These studies underscore the importance and utility of using genetic single and double $\mathrm{KO}$ mice to delineate the respective function of GRPR and NMBR in pruriceptive transmission.

The aforementioned cross-inhibition occurs at the level of agonist-receptor interaction rather than at the level of circuits. How does cross-inhibition of the receptor signaling manifest the functional output of the itch circuit? Apart from $\mathrm{GRPR}^{+}$neurons and TR $4^{+}$neurons (Sun et al., 2009; Wang et al., 2013; Zhao et al., 2013), $\mathrm{NMBR}^{+}$neurons represent a new population of excitatory interneurons that is closely related to GRPR ${ }^{+}$neurons and is important for histaminerigic itch transmission in the spinal cord. Several pieces of evidence suggest that $\mathrm{NMBR}^{+}$neurons may function at least in part as an upstream station of GRPR ${ }^{+}$ neurons. First, coinjection of GRP and NMB fails to produce an additive effect. Rather, the number of scratching bouts evoked by GRP and NMB together is similar to that evoked by GRP alone. Consistently, the time course curve of GRP masks that of NMB, indicating that it is $\mathrm{GRPR}^{+}$neurons instead of $\mathrm{NMBR}^{+}$neurons that serve as a "gate" for controlling the itch output in the spinal cord. Second, the findings that ablation of GRPR ${ }^{+}$neurons abolishes histaminergic itch further supports that the output of $\mathrm{NMBR}^{+}$neurons is dependent on GRPR ${ }^{+}$neurons. The surpris- ing finding that intrathecal NMB still evokes a significant amount of scratching in mice treated with Bn-sap suggests that $\mathrm{NMBR}^{+}$ neurons may contact projection neurons directly to evoke scratching behavior. However, the synaptic contacts between $\mathrm{NMBR}^{+}$interneurons and projection neurons are not physiologically significant because mice treated with Bn-sap are unable to respond to peripherally derived pruritogenic stimuli. Consistently, ablation of $\mathrm{NMBR}^{+}$neurons fails to impair histaminergic itch (Mishra et al., 2012), further supporting that GRPR ${ }^{+}$neurons are necessary and sufficient for relaying histaminergic itch (Fig. 8B). Importantly, GRPR ${ }^{+}$neurons are able to integrate histaminergic information encoded by NMB-NMBR signaling, when $\mathrm{NMBR}^{+}$neurons are also present, to modulate the total output of itch signaling when both pathways are engaged (Fig. $8 B)$. Therefore, although $\mathrm{NMBR}^{+}$neurons act upstream of $\mathrm{GRPR}^{+}$neurons to participate in histaminergic itch signaling, they are also dispensable for histaminergic itch. On the other hand, when Grpr is absent, histaminergic itch information will be transmitted via the NMB-NMBR pathway (Fig. $8 C$ ). Finally, in chronic itch conditions, a lack of either GRPR or GRPR ${ }^{+}$neurons is sufficient to block itch transmission (Sun et al., 2009; Lagerström et al., 2010; Zhao et al., 2013), further supporting a critical role for GRPR and GRPR ${ }^{+}$neurons in control of the output of pruriceptive information. These results suggest a great plasticity for the dorsal horn neurons to process histaminergic itch information.

$\mathrm{GRPR}^{+}$neurons are required for mediating both histaminergic and nonhistaminergic itch (Sun et al., 2009). In primates, 
spinothalamic tract neurons can be classified into the following two separate populations: histamine sensitive and cowhage sensitive (a histamine-independent pruritogen; Davidson et al., 2007). It is possible that $\mathrm{GRPR}^{+}$neurons may comprise histamine-sensitive and histamine-insensitive subpopulations. The finding that $~ 30 \%$ of $\mathrm{GRPR}^{+}$neurons express MOR1D, an isoform that is required for morphine-induced itch (Liu et al., 2011), suggests that $\mathrm{GRPR}^{+}$neurons are heterogeneous. Our studies also support the idea that GRP-GRPR signaling exerts a broader and dominant function in itch signaling compared with NMB-NMBR signaling. Interestingly, the relegated and limited role of NMB-NMBR signaling relative to GRP-GRPR signaling has also been shown in other physiological functions such as thermoregulation, smooth muscle contraction, and satiety (Bishop et al., 1986; Hampton et al., 1998; Ohki-Hamazaki et al., 1999; Ohki-Hamazaki, 2000). These studies suggest that NMB-NMBR signaling may have a generic role in negative modulation of GRP-GRPR signaling via partial blockade of GRP-GRPR signaling.

In conclusion, our studies suggest that functional antagonism of the NMBR and GRPR pathways underlies normal histaminergic itch transmission, while GRPR possesses a unique role in nonhistaminergic itch. The findings provide mechanistic insights into "lack of phenotype" when one of the multiple excitatory receptors of the same family is deleted, which has frequently been conveniently explained by genetic/developmental compensation or neural plasticity. In this regard, our study may have a proofof-principle implication for our understanding of how neural circuitry keeps its activity to maintain normal homeostasis. Finally, we provide evidence suggesting that GRPR ${ }^{+}$neurons serve as a key relay station that acts downstream of $\mathrm{NMBR}^{+}$neurons to transmit histaminergic itch signal. Therefore, the dorsal horn circuitry is regulated at both receptor and circuit levels to ensure high-fidelity transmission of pruriceptive information to the brain.

\section{References}

Akiyama T, Carstens E (2013) Neural processing of itch. Neuroscience 250: 697-714. CrossRef Medline

Akiyama T, Tominaga M, Takamori K, Carstens MI, Carstens E (2014) Roles of glutamate, substance $\mathrm{P}$ and gastrin releasing peptide as spinal neurotransmitters of histaminergic and non-histaminergic itch. Pain 155: 80-92. CrossRef Medline

Battey J, Wada E (1991) Two distinct receptor subtypes for mammalian bombesin-like peptides. Trends Neurosci 14:524-528. CrossRef Medline

Bautista DM, Wilson SR, Hoon MA (2014) Why we scratch an itch: the molecules, cells and circuits of itch. Nat Neurosci 17:175-182. CrossRef Medline

Bernstein SL, Koo JH, Slater BJ, Guo Y, Margolis FL (2006) Analysis of optic nerve stroke by retinal Bex expression. Mol Vis 12:147-155. Medline

Bishop JF, Moody TW, O’Donohue TL (1986) Peptide transmitters of primary sensory neurons: similar actions of tachykinins and bombesin-like peptides. Peptides 7:835-842. CrossRef Medline

Braz J, Solorzano C, Wang X, Basbaum AI (2014) Transmitting pain and itch messages: a contemporary view of the spinal cord circuits that generate gate control. Neuron 82:522-536. CrossRef Medline

Cardell M, Landsend AS, Eidet J, Wieloch T, Blackstad TW, Ottersen OP (1998) High resolution immunogold analysis reveals distinct subcellular compartmentation of protein kinase $\mathrm{C}$ gamma and delta in rat Purkinje cells. Neuroscience 82:709-725. Medline

Casini G, Rickman DW, Sternini C, Brecha NC (1997) Neurokinin 1 receptor expression in the rat retina. J Comp Neurol 389:496-507. CrossRef Medline

Casini G, Dal Monte M, Fornai F, Bosco L, Willems D, Yang Q, Zhou ZJ, Bagnoli P (2004) Neurokinin 1 receptor expression and substance P physiological actions are developmentally regulated in the rabbit retina. Neuroscience 124:147-160. CrossRef Medline

Catalani E, Dal Monte M, Gangitano C, Lucattelli M, Fineschi S, Bosco L,
Bagnoli P, Casini G (2006) Expression of substance P, neurokinin 1 receptors (NK1) and neurokinin 3 receptors in the developing mouse retina and in the retina of NK1 knockout mice. Neuroscience 138:487-499. CrossRef Medline

Chen ZF, Rebelo S, White F, Malmberg AB, Baba H, Lima D, Woolf CJ, Basbaum AI, Anderson DJ (2001) The paired homeodomain protein DRG11 is required for the projection of cutaneous sensory afferent fibers to the dorsal spinal cord. Neuron 31:59-73. CrossRef Medline

Davidson S, Zhang X, Yoon CH, Khasabov SG, Simone DA, Giesler GJ Jr (2007) The itch-producing agents histamine and cowhage activate separate populations of primate spinothalamic tract neurons. J Neurosci 27: 10007-10014. CrossRef Medline

Erickson CS, Zaitoun I, Haberman KM, Gosain A, Druckenbrod NR, Epstein ML (2012) Sacral neural crest-derived cells enter the aganglionic colon of Ednrb-/- mice along extrinsic nerve fibers. J Comp Neurol 520:620 632. CrossRef Medline

Fleming MS, Ramos D, Han SB, Zhao J, Son YJ, Luo W (2012) The majority of dorsal spinal cord gastrin releasing peptide is synthesized locally whereas neuromedin B is highly expressed in pain- and itch-sensing somatosensory neurons. Mol Pain 8:52. CrossRef Medline

Fremeau RT Jr, Troyer MD, Pahner I, Nygaard GO, Tran CH, Reimer RJ, Bellocchio EE, Fortin D, Storm-Mathisen J, Edwards RH (2001) The expression of vesicular glutamate transporters defines two classes of excitatory synapse. Neuron 31:247-260. CrossRef Medline

Gonzalez N, Moody TW, Igarashi H, Ito T, Jensen RT (2008) Bombesinrelated peptides and their receptors: recent advances in their role in physiology and disease states. Curr Opin Endocrinol Diabetes Obes 15:58 - 64. CrossRef Medline

Grill R, Murai K, Blesch A, Gage FH, Tuszynski MH (1997) Cellular delivery of neurotrophin-3 promotes corticospinal axonal growth and partial functional recovery after spinal cord injury. J Neurosci 17:5560-5572. Medline

Hampton LL, Ladenheim EE, Akeson M, Way JM, Weber HC, Sutliff VE, Jensen RT, Wine LJ, Arnheiter H, Battey JF (1998) Loss of bombesininduced feeding suppression in gastrin-releasing peptide receptordeficient mice. Proc Natl Acad Sci U S A 95:3188-3192. CrossRef Medline

Han SK, Simon MI (2011) Intracellular signaling and the origins of the sensations of itch and pain. Sci Signal 4:pe38. CrossRef Medline

Holland PW, Garcia-Fernandez J, Williams NA, Sidow A (1994) Gene duplications and the origins of vertebrate development. Dev Suppl 125-133.

Jeffry JA, Yu SQ, Sikand P, Parihar A, Evans MS, Premkumar LS (2009) Selective targeting of TRPV1 expressing sensory nerve terminals in the spinal cord for long lasting analgesia. PLoS One 4:e7021. CrossRef Medline

Jeffry J, Kim S, Chen ZF (2011) Itch signaling in the nervous system. Physiology (Bethesda) 26:286-292. CrossRef

Jensen RT, Battey JF, Spindel ER, Benya RV (2008) International Union of Pharmacology. LXVIII. Mammalian bombesin receptors: nomenclature, distribution, pharmacology, signaling, and functions in normal and disease states. Pharmacol Rev 60:1-42. CrossRef Medline

Kagami S, Sugaya M, Suga H, Morimura S, Kai H, Ohmatsu H, Fujita H, Tsunemi Y, Sato S (2013) Serum gastrin-releasing peptide levels correlate with pruritus in patients with atopic dermatitis. J Invest Dermatol 133:1673-1675. CrossRef Medline

Koga K, Chen T, Li XY, Descalzi G, Ling J, Gu J, Zhuo M (2011) Glutamate acts as a neurotransmitter for gastrin releasing peptide-sensitive and insensitive itch-related synaptic transmission in mammalian spinal cord. Mol Pain 7:47. CrossRef Medline

Kroog GS, Jensen RT, Battey JF (1995) Mammalian bombesin receptors. Med Res Rev 15:389-417. CrossRef Medline

Lagerström MC, Rogoz K, Abrahamsen B, Persson E, Reinius B, Nordenankar K, Olund C, Smith C, Mendez JA, Chen ZF, Wood JN, Wallén-Mackenzie A, Kullander K (2010) VGLUT2-dependent sensory neurons in the TRPV1 population regulate pain and itch. Neuron 68:529-542. CrossRef Medline

Li JL, Ding YQ, Shigemoto R, Mizuno N (1996) Distribution of trigeminothalamic and spinothalamic-tract neurons showing substance $\mathrm{P}$ receptor-like immunoreactivity in the rat. Brain Res 719:207-212. CrossRef Medline

Liu Q, Tang Z, Surdenikova L, Kim S, Patel KN, Kim A, Ru F, Guan Y, Weng HJ, Geng Y, Undem BJ, Kollarik M, Chen ZF, Anderson DJ, Dong X 
(2009) Sensory neuron-specific GPCR Mrgprs are itch receptors mediating chloroquine-induced pruritus. Cell 139:1353-1365. CrossRef Medline

Liu T, Berta T, Xu ZZ, Park CK, Zhang L, Lü N, Liu Q, Liu Y, Gao YJ, Liu YC, Ma Q, Dong X, Ji RR (2012) TLR3 deficiency impairs spinal cord synaptic transmission, central sensitization, and pruritus in mice. J Clin Invest 122:2195-2207. CrossRef Medline

Liu XY, Liu ZC, Sun YG, Ross M, Kim S, Tsai FF, Li QF, Jeffry J, Kim JY, Loh HH, Chen ZF (2011) Unidirectional cross-activation of GRPR by MOR1D uncouples itch and analgesia induced by opioids. Cell 147:447458. CrossRef Medline

Liu XY, Wan L, Huo FQ, Barry DM, Li H, Zhao ZQ, Chen ZF (2014) B-type natriuretic peptide is neither itch-specific nor functions upstream of the GRP-GRPR signaling pathway. Mol Pain 10:4. CrossRef Medline

Marvizón JC, Chen W, Murphy N (2009) Enkephalins, dynorphins, and $\beta$-endorphin in the rat dorsal horn: an immunofluorescence colocalization study. J Comp Neurol 517:51-68. CrossRef Medline

Miklos GL, Rubin GM (1996) The role of the genome project in determining gene function: insights from model organisms. Cell 86:521-529. CrossRef Medline

Mishra SK, Hoon MA (2013) The cells and circuitry for itch responses in mice. Science 340:968-971. CrossRef Medline

Mishra SK, Holzman S, Hoon MA (2012) A nociceptive signaling role for neuromedin B. J Neurosci 32:8686-8695. CrossRef Medline

Moody TW, Merali Z (2004) Bombesin-like peptides and associated receptors within the brain: distribution and behavioral implications. Peptides 25:511-520. CrossRef Medline

Moody TW, Leyton J, Garcia-Marin L, Jensen RT (2003) Nonpeptide gastrin releasing peptide receptor antagonists inhibit the proliferation of lung cancer cells. Eur J Pharmacol 474:21-29. CrossRef Medline

Nattkemper LA, Zhao ZQ, Nichols AJ, Papoiu AD, Shively CA, Chen ZF, Yosipovitch $G$ (2013) Overexpression of the gastrin-releasing peptide in cutaneous nerve fibers and its receptor in the spinal cord in primates with chronic itch. J Invest Dermatol 133:2489-2492. CrossRef Medline

O’Donohue TL, Massari VJ, Pazoles CJ, Chronwall BM, Shults CW, Quirion R, Chase TN, Moody TW (1984) A role for bombesin in sensory processing in the spinal cord. J Neurosci 4:2956-2962. Medline

Ohki-Hamazaki H (2000) Neuromedin B. Prog Neurobiol 62:297-312. CrossRef Medline

Ohki-Hamazaki H, Sakai Y, Kamata K, Ogura H, Okuyama S, Watase K, Yamada K, Wada K (1999) Functional properties of two bombesin-like peptide receptors revealed by the analysis of mice lacking neuromedin B receptor. J Neurosci 19:948-954. Medline

Osada S, Mizuno K, Saido TC, Suzuki K, Kuroki T, Ohno S (1992) A new member of the protein kinase $\mathrm{C}$ family, nPKC theta, predominantly expressed in skeletal muscle. Mol Cell Biol 12:3930-3938. Medline

Reisfeld RA, Börjeson J, Chessin LN, Small PA Jr (1967) Isolation and characterization of a mitogen from pokeweek (Phytolacca americana). Proc Natl Acad Sci U S A 58:2020-2027. CrossRef Medline

Su PY, Ko MC (2011) The role of central gastrin-releasing peptide and neuromedin $\mathrm{B}$ receptors in the modulation of scratching behavior in rats. J Pharmacol Exp Ther 337:822-829. CrossRef Medline

Sukhtankar DD, Ko MC (2013) Physiological function of gastrin-releasing Peptide and neuromedin B receptors in regulating itch scratching behavior in the spinal cord of mice. PLoS One 8:e67422. CrossRef Medline
Sun YG, Chen ZF (2007) A gastrin-releasing peptide receptor mediates the itch sensation in the spinal cord. Nature 448:700-703. CrossRef Medline

Sun YG, Zhao ZQ, Meng XL, Yin J, Liu XY, Chen ZF (2009) Cellular basis of itch sensation. Science 325:1531-1534. CrossRef Medline

Takanami K, Sakamoto H, Matsuda KI, Satoh K, Tanida T, Yamada S, Inoue K, Oti T, Sakamoto T, Kawata M (2014) Distribution of gastrinreleasing peptide in the rat trigeminal and spinal somatosensory systems. J Comp Neurol 522:1858-1873. CrossRef Medline

Todd AJ (2010) Neuronal circuitry for pain processing in the dorsal horn. Nat Rev Neurosci 11:823-836. CrossRef Medline

Todd AJ, McGill MM, Shehab SA (2000) Neurokinin 1 receptor expression by neurons in laminae I, III and IV of the rat spinal dorsal horn that project to the brainstem. Eur J Neurosci 12:689-700. CrossRef Medline

Tseng YY, Gruzdeva N, Li A, Chuang JZ, Sung CH (2010) Identification of the Tctex-1 regulatory element that directs expression to neural stem/ progenitor cells in developing and adult brain. J Comp Neurol 518:33273342. CrossRef Medline

Vigna SR, Bowden JJ, McDonald DM, Fisher J, Okamoto A, McVey DC, Payan DG, Bunnett NW (1994) Characterization of antibodies to the rat substance-P (NK-1) receptor and to a chimeric substance-P receptor expressed in mammalian cells. J Neurosci 14:834-845. Medline

Vilotti S, Marchenkova A, Ntamati N, Nistri A (2013) B-type natriuretic peptide-induced delayed modulation of TRPV1 and P2X3 receptors of mouse trigeminal sensory neurons. PLoS One 8:e81138. CrossRef Medline

Wang S, Hazelrigg T (1994) Implications for bcd mRNA localization from spatial distribution of exu protein in Drosophila oogenesis. Nature 369: 400-403. CrossRef Medline

Wang X, Zhang J, Eberhart D, Urban R, Meda K, Solorzano C, Yamanaka H, Rice D, Basbaum AI (2013) Excitatory superficial dorsal horn interneurons are functionally heterogeneous and required for the full behavioral expression of pain and itch. Neuron 78:312-324. CrossRef Medline

Wiley RG, Kline RH IV (2000) Neuronal lesioning with axonally transported toxins. J Neurosci Methods 103:73-82. CrossRef Medline

Woodbury CJ, Kullmann FA, McIlwrath SL, Koerber HR (2008) Identity of myelinated cutaneous sensory neurons projecting to nocireceptive laminae following nerve injury in adult mice. J Comp Neurol 508:500-509. CrossRef Medline

Zhang FX, Liu XJ, Gong LQ, Yao JR, Li KC, Li ZY, Lin LB, Lu YJ, Xiao HS, Bao L, Zhang XH, Zhang X (2010) Inhibition of inflammatory pain by activating B-type natriuretic peptide signal pathway in nociceptive sensory neurons. J Neurosci 30:10927-10938. CrossRef Medline

Zhao ZQ, Scott M, Chiechio S, Wang JS, Renner KJ, Gereau RW 4th, Johnson RL, Deneris ES, Chen ZF (2006) Lmx1b is required for maintenance of central serotonergic neurons and mice lacking central serotonergic system exhibit normal locomotor activity. J Neurosci 26:12781-12788. CrossRef Medline

Zhao ZQ, Huo FQ, Jeffry J, Hampton L, Demehri S, Kim S, Liu XY, Barry DM, Wan L, Liu ZC, Li H, Turkoz A, Ma K, Cornelius LA, Kopan R, Battey JF Jr, Zhong J, Chen ZF (2013) Chronic itch development in sensory neurons requires BRAF signaling pathways. J Clin Invest 123:4769-4780. CrossRef Medline

Zylka MJ, Rice FL, Anderson DJ (2005) Topographically distinct epidermal nociceptive circuits revealed by axonal tracers targeted to Mrgprd. Neuron 45:17-25. CrossRef Medline 